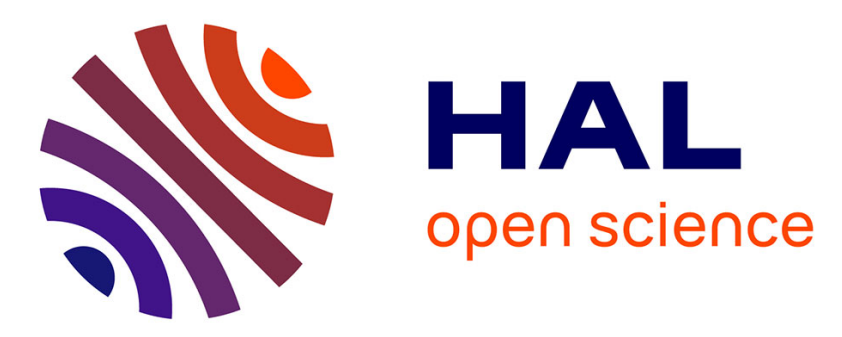

\title{
Combination of Lutein and Zeaxanthin, and DHA Regulated Polyunsaturated Fatty Acid Oxidation in H2O2-Stressed Retinal Cells
}

Ho Hang Leung, Jean-Marie Galano, Céline Crauste, Thierry Durand, Jetty Chung-Yung Lee

\section{To cite this version:}

Ho Hang Leung, Jean-Marie Galano, Céline Crauste, Thierry Durand, Jetty Chung-Yung Lee. Combination of Lutein and Zeaxanthin, and DHA Regulated Polyunsaturated Fatty Acid Oxidation in H2O2-Stressed Retinal Cells. Neurochemical Research, 2020, 45 (5), pp.1007-1019. 10.1007/s11064020-02994-4 . hal-02592871

\section{HAL Id: hal-02592871 \\ https://hal.science/hal-02592871}

Submitted on 15 May 2020

HAL is a multi-disciplinary open access archive for the deposit and dissemination of scientific research documents, whether they are published or not. The documents may come from teaching and research institutions in France or abroad, or from public or private research centers.
L'archive ouverte pluridisciplinaire HAL, est destinée au dépôt et à la diffusion de documents scientifiques de niveau recherche, publiés ou non, émanant des établissements d'enseignement et de recherche français ou étrangers, des laboratoires publics ou privés. 


\title{
Combination of Lutein and Zeaxanthin, and DHA Regulated Polyunsaturated Fatty Acid Oxidation in $\mathrm{H}_{2} \mathrm{O}_{2}$-Stressed Retinal Cells
}

\author{
Ho Hang Leung ${ }^{1} \cdot$ Jean-Marie Galano ${ }^{2} \cdot$ Céline Crauste $^{2} \cdot$ Thierry Durand $^{2} \cdot$ Jetty Chung-Yung Lee ${ }^{1}[0$
}

\begin{abstract}
Photochemical and oxidative damages in retinal pigment epithelial (RPE) cells are key events in the pathogenesis of agerelated macular degeneration. Polyunsaturated fatty acids (PUFA) and carotenoids are rich in retinal cells, and under oxidative stress leads to oxidation and release lipid mediators. We evaluated the impact of carotenoids (lutein, zeaxanthin) and docosahexaenoic acid (DHA) supplementation on RPE cells under oxidative stress. ARPE-19 cells were exposed to $\mathrm{H}_{2} \mathrm{O}_{2}$ after pretreatment with lutein, zeaxanthin, DHA, lutein + zeaxanthin or lutein + zeaxanthin with DHA. The data showed $\mathrm{H}_{2} \mathrm{O}_{2}$ reduced cell viability and DHA content, while promoted catalase activity and certain oxidized PUFA products. Treatment with DHA enhanced omega-3 PUFA enzymatic oxidation namely, anti-inflammatory mediators such as hydroxy-DHA, resolvins and neuroprotection compared to control; the effects were not influenced by the carotenoids. Omega-6 PUFA oxidation, namely pro-inflammatory HETE (5-, 9-, 12 and 20-HETE), and isoprostanes (5- and $15-\mathrm{F}_{2 \mathrm{t}}-\mathrm{IsoP}$ and $4-\mathrm{F}_{3 \mathrm{t}}-\mathrm{IsoP}$ ) were reduced by lutein + zeaxanthin while the addition of DHA did not further reduce these effects. We observed transcriptional regulation of 5-lipoxygenase by DHA and GPx1 and NEFEL2 by the carotenoids that potentially resulted in decreased HETEs and glutathione respectively. 4-HNE was not affected by the treatments but 4-HHE was reduced by lutein + zeaxanthin with and without DHA. To conclude, carotenoids and DHA appeared to regulate inflammatory lipid mediators while the carotenoids also showed benefits in reducing non-enzymatic oxidation of omega-6 PUFA.
\end{abstract}

Keywords ARPE-19 - Oxidative stress · Macular degeneration · Carotenoids · DHA · Glutathione

\section{Introduction}

Age-related macular degeneration (AMD) is an ocular disease and the leading cause of visual impairment in most developed countries [1]. There are two stages of AMD, atrophic and exudative AMD, in which patients typically have atrophic AMD first and progress to exudative AMD. To date, a major risk factor for the development of AMD is

Electronic supplementary material The online version of this article (https://doi.org/10.1007/s11064-020-02994-4) contains supplementary material, which is available to authorized users.

Jetty Chung-Yung Lee jettylee@hku.hk

1 School of Biological Sciences, The University of Hong Kong, Pokfulam Road, Hong Kong SAR, China

2 Institut Des Biomolécules Max Mousseron, UMR 5247, CNRS, ENSCM, Université de Montpellier, Montpellier, France aging [2]. Other lifestyle factors such as cigarette smoking and dietary habits also contribute to the disease progression [3, 4]. Population-based clinical trials showed combination of dietary antioxidants (including vitamins, metal ions, and carotene) delays the progression of advanced AMD [5, 6]. Other epidemiological studies also suggest carotenoids i.e. lutein and zeaxanthin [7] and omega-3 polyunsaturated fatty acids (PUFAs) take part in disease protection [8, 9]. In a recent clinical study, supplementation of high dose eicosapentaenoic acid + docosahexaenoic acid (EPA + DHA) reduced AMD progression [10].

The pathophysiology of AMD is featured with gradual degradation of retinal pigment epithelial (RPE) and adjacent photoreceptor cells [11]. Oxidative and photochemical damage to the macula induces drusen formation; an extracellular debris containing modified proteins and lipids [12], which prevents nutrient exchange and create local inflammation. AMD studies use acute RPE cells (ARPE-19) to investigate molecular events [13]. A few reports focused on cellular changes in ARPE-19 upon oxidative challenge $[14,15]$, where $\mathrm{G} 2 / \mathrm{M}$ phase was 
arrested and cell damage by $\mathrm{H}_{2} \mathrm{O}_{2}$ were seen, while supplementation of lutein or DHA counteracted the apoptosis. Knowing that photoreceptors and adjacent RPE cells are abundant in DHA and susceptible to oxidative stress, it is of interest to know whether oxidation products from DHA and other PUFAs contribute to the pathophysiology of AMD.

Numerous oxidized PUFA products are classified as lipid mediators that take part in modulating molecular pathways (Figs. A1, A2, Online Appendix) [16]. Those originating from lipoxygenase-mediated PUFA oxidation are regulators of inflammatory response where hydroxyeicosatetraenoic acids (HETE) derived from arachidonic acid (ARA) are pro-inflammatory and activate platelets, while DHA-derived hydroxydocosahexaenoic acids (HDHA) are anti-inflammatory with pro-resolving actions [17]. It was noted, 4-HDHA produced by 5-lipoxygenase in an in vitro system displayed inhibitory effect on angiogenesis, a key event associated exudative AMD pathogenesis [18]

In non-enzymatic oxidation, ARA-derived $15-\mathrm{F}_{2 \mathrm{t}}$-isoprostane $\left(15-\mathrm{F}_{2 \mathrm{t}}\right.$-IsoP) is not only a biomarker for oxidative stress in vivo but also an effective vasoconstrictor in the pathogenesis of cardiovascular diseases by activating TP receptor signalling.[16, 19, 20]. Other isoprostane groups, including $\mathrm{F}_{2}$-dihomo-isoprostanes $\left(\mathrm{F}_{2}\right.$-dihomo-IsoP) from adrenic acid (AdA), $\mathrm{F}_{3}$-isoprostanes $\left(\mathrm{F}_{3}\right.$-IsoP) from EPA, and $\mathrm{F}_{4}$-neuroprostanes $\left(\mathrm{F}_{4}-\mathrm{NeuroP}\right)$ from $\mathrm{DHA}$ are also considered biomarkers of oxidative stress-related neurological diseases. In addition, $4-\mathrm{F}_{4 \mathrm{t}}-\mathrm{NeuroP}$ showed to be beneficial in the cardiovascular system [16, 21, 22].

Genomic studies showed certain signalling pathways participate in the development of AMD [23]. Particularly, peroxisome proliferator-activated receptor (PPAR) and nuclear factor E2-related factor 2 (Nrf2) pathways are of interest. PPAR $\gamma$ is known to be constitutively expressed in normal RPE cells, and tends to be up-regulated in AMD patients [24]. On the other hand, the Nrf2 pathway is implicated in AMD due to its ability to modulate multiple antioxidant enzymes [25]. Some studies have reported that therapeutic compounds of AMD act through Nrf2 pathway activation [26, 27].

In this pilot study, we investigated the potential roles of carotenoids and DHA by determining oxidized PUFA products related to antioxidant and inflammatory process, and cellular signalling in oxidative stressed ARPE-19 cells to evaluate its potential contribution to AMD development.

\section{Materials and Methods}

\section{Chemicals and Materials}

Chemicals and materials including sources and grade are described in Online Appendix. Novel oxidized PUFA compounds used for the LC-QToF-MS/MS analysis were synthesized [28] by Institut des Biomolécules Max Mousseron group (IBMM, Montpellier, France).

\section{ARPE-19 Cell Culture and Treatments}

ARPE-19 cells were maintained in DMEM/Ham F12 containing FBS (10\% v/v) and antibiotics (1\% v/v) in $5 \% \mathrm{CO}_{2}$ humidified at $37{ }^{\circ} \mathrm{C}$. The cell passage number was kept at a range of $10-20$ to prevent significant morphological and functional modifications.

The cells were seeded in 96-well plates for $24 \mathrm{~h}$ before treatments and then cultured with serum-free medium containing lutein $(0,2.5,5,10,20,40 \mu \mathrm{M})$, zeaxanthin $(0,2.5$, $5,10,20,40 \mu \mathrm{M})$, and DHA $(0,10,25,50,100 \mu \mathrm{M})$ for $24 \mathrm{~h}$. Using MTT assay, the optimal dose was selected for all treatments. The treated cells were washed with PBS (pH 7.4) and challenged with $\mathrm{H}_{2} \mathrm{O}_{2}(600 \mu \mathrm{M})$ for $1 \mathrm{~h}$ prior testing. Lutein, zeaxanthin, and DHA were prepared in DMSO (0.1\%). Control cells were incubated with serum-free medium containing $0.1 \%$ DMSO.

\section{3-(4,5-Dimethylthiazol-2-yl)-2,5-diphenyltetrazo- lium Bromide (MTT) Assay}

Cell viability was determined using MTT colorimetric assay. After incubation for $4 \mathrm{~h}$ with MTT $(0.5 \mathrm{mg} / \mathrm{mL})$, the purple formazan produced was dissolved in DMSO. The absorbance (570 nm and $655 \mathrm{~nm}$ ) was measured using microplate reader (BioRad 550, USA). Viable cells were expressed as percentage to control cells (100\%).

\section{Measurement of Fatty Acids and Oxidized PUFA Products}

The cell samples were prepared and quantified using liquid chromatography quadrupole time-of-flight tandem mass spectrometry (LC-QToF-MS/MS) method [28] with modifications as described in Online Appendix. Fatty acids (oleic, linoleic, ARA, AdA, docosapentaenoic, EPA, DHA), isoprostanes (IsoP), HETE, HDHA, resolvins, neuroprotectin and aldehydes (as listed in Table A1 in Online Appendix) levels were determined.

\section{Glutathione (GSH), Superoxide Dismutase (SOD), Catalase (CAT) Measurements}

The treated cells were prepared and measured for GSH, SOD and CAT activities (Cayman Chemical, MI USA), and standardized with protein concentrations (BCA Protein Assay Kit, Abcam, USA). The measurement of GSH involved the enzymatic recycling of GSH [29]. The sulfhydryl group of GSH reacts with 5,5'-dithio-bis-2-nitrobenzoic acid (DTNB), producing a complex of GS-TNB and 5-thio-2-nitrobenzoic 
acid (TNB), monitored by spectrophotometric (Biochrom $\mathrm{S} 12, \mathrm{UK})$ absorbance at $405-414 \mathrm{~nm}$. The activity of SOD is frequently determined by utilizing the xanthine/xanthine oxidase system to produce superoxide anions and the formation of purple formazan from water soluble tetrazolium salt [30], monitored by the measurement of spectrophotometric absorbance at $440-460 \mathrm{~nm}$. The measurement of CAT level is based on the peroxidatic activity of CAT with methanol in the presence of $\mathrm{H}_{2} \mathrm{O}_{2}$, where the formaldehyde produced is capable to bind with 4-amino-3-hydrazino-5-mercapto-1,2,4-triazole (Purpald) and form a bicyclic heterocycle chromogen [31, 32], detected by spectrophotometric absorbance at $540 \mathrm{~nm}$.

\section{Protein Standardization}

It is common to normalize the GSH, SOD and CAT results with protein levels using bicinchoninic acid (BCA) assay. BCA assay is based on the reduction of copper (II) ions into copper (I) ions by peptide bonds in sample proteins. The chelation between BCA and copper (I) ions form a purple matrix [33] which is monitored by the absorbance at $562 \mathrm{~nm}$ using a spectrophotometer (Biochrom S12, UK).

\section{Quantitative PCR}

Quantitative PCR was performed using $1 \mu \mathrm{L}$ cDNA generated by RT-PCR [28]. Applied Biosystems ${ }^{\mathrm{TM}}$ Power $^{\mathrm{TM}}$ SYBR ${ }^{\mathrm{TM}}$ Green Master Mix (Thermo Fisher, USA) was used for the amplification (as listed in Table A2, Online Appendix). The reaction was carried out for 45 cycles: $60{ }^{\circ} \mathrm{C}$ for $30 \mathrm{~s}, 95^{\circ} \mathrm{C}$ for $2 \mathrm{~min}, 95^{\circ} \mathrm{C}$ for $15 \mathrm{~s}$ and $60^{\circ} \mathrm{C}$ for $40 \mathrm{~s}$. RNA18SN5 (Gene ID: $100,008,588$ ) was used to normalize the expression levels. Reactions and analysis were performed on a StepOnePlus Real-Time PCR System (ABI, USA).

\section{Statistical Analysis}

Statistical analysis was performed by SPSS (version 25.0 Windows, USA). Data is expressed as mean (standard derivation). Concentrations of oxidized PUFA products, antioxidants and gene expressions between treatment groups were compared using one-way ANOVA while student t-test was applied to compare the difference within each group, with or without hydrogen peroxide. A $p$-value of 0.05 or less were considered statistically significant.

\section{Results}

\section{DHA Increased ARPE-19 Cell Proliferation Even Under Oxidative Stress}

Hydrogen peroxide $(0-1000 \mu \mathrm{M})$ was added to the culture medium for $1 \mathrm{~h}$. As shown in Fig. 1a, when the concentration reached $600 \mu \mathrm{M}$, the cell viability reduced to approximately $50 \%$ of the control group. Thereby, $600 \mu \mathrm{M} \mathrm{H}_{2} \mathrm{O}_{2}$ was selected for the study. The concentration of lutein, zeaxanthin or DHA treatments that retained maximum viability was also selected (Fig. 1b) where it was found to be $10 \mu \mathrm{M}$ lutein, $10 \mu \mathrm{M}$ zeaxanthin, and $25 \mu \mathrm{M}$ DHA.

When the cells were treated with $10 \mu \mathrm{M}$ lutein and $10 \mu \mathrm{M}$ zeaxanthin and challenged with $\mathrm{H}_{2} \mathrm{O}_{2}$, viability enhanced by $20.1 \%$ and $26.5 \%$ respectively, compared to $\mathrm{H}_{2} \mathrm{O}_{2}$ alone (Fig. 1c). Treatment of $25 \mu \mathrm{M}$ DHA increased the cell viability to near basal level (Fig. 1c). Since lutein and zeaxanthin co-exist in the retina [34] and both are associated with a lower risk of AMD [4], the synergistic effect was also tested. The cell viability and proliferation of RPE cells remained unchanged with concentrations co-treated with lutein/zeaxanthin up to $10 / 10 \mu \mathrm{M}$ while 20/20 $\mu \mathrm{M}$ was cytotoxic (Fig. 1d). Addition of $\mathrm{H}_{2} \mathrm{O}_{2}$ did not reduce or increase cell proliferation when pre-treated with lutein/zeaxanthin for all concentrations. Along with the carotenoids, it was suggested DHA also take part in maintaining healthy retinal cells [35]. A combination of $10 / 10 / 12.5 \mu \mathrm{M}$ lutein/zeaxanthin/DHA suppressed the proliferation with or without $\mathrm{H}_{2} \mathrm{O}_{2}$ challenge (Fig. 1e) whereas, higher DHA i.e., 10/10/25 $\mu \mathrm{M}$ of lutein/zeaxanthin/DHA prevented the inhibition but was unable to return to basal level (Fig. 1e).

\section{Omega-3 PUFA was Modified by DHA Treatment}

Levels of oleic acid and omega-6 PUFA namely linoleic acid, ARA and AdA were not altered by lutein, zeaxanthin or DHA treatment, even when combined. Furthermore, the challenge by $\mathrm{H}_{2} \mathrm{O}_{2}$ did not significantly change these levels, and instead, those treated with zeaxanthin significantly increased the linoleic acid concentration compared to lutein treatment (Table 1).

As anticipated, treatment of $25 \mu \mathrm{M}$ DHA significantly increased the cellular DHA levels compared to control, lutein, zeaxanthin or lutein + zeaxanthin. DHA elevation was also seen when it was added to lutein + zeaxanthin (Table 1). In addition, docosapentaenoic acid (DPA $\left.A_{n-3}\right)$ levels were augmented by DHA compared to zeaxanthin, zeaxanthin or lutein + zeaxanthin with or without DHA in the presence or absence of $\mathrm{H}_{2} \mathrm{O}_{2}$. Interestingly, EPA levels 

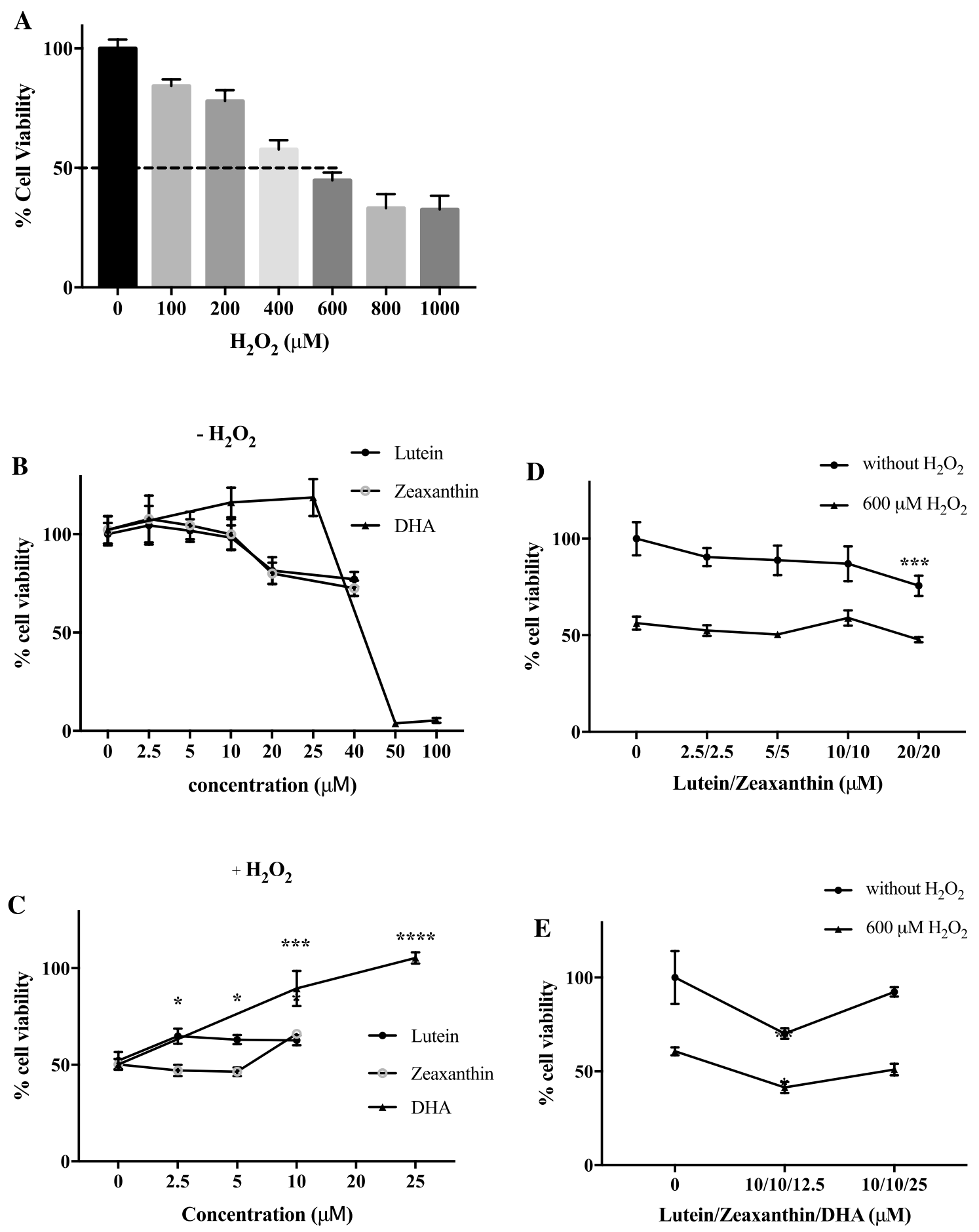

Fig. 1 Viability (\%) of RPE cells $(n=4)$ after a exposure to different concentrations of $\mathrm{H}_{2} \mathrm{O}_{2}(100$ to $1000 \mu \mathrm{M})$ for $1 \mathrm{~h}$; b 24 h lutein, zeaxanthin, or DHA treatment; c $24 \mathrm{~h}$ lutein, zeaxanthin, or DHA treatment and then exposed to $600 \mu \mathrm{M} \mathrm{H}_{2} \mathrm{O}_{2}$ for $1 \mathrm{~h} .{ }^{*} \mathrm{p}<0.05$, $* * * \mathrm{p}<0.001$ vs control $(0 \mu \mathrm{M}) ; \mathbf{d} 24 \mathrm{~h}$ treatment with lutein plus

were enhanced by DHA treatment compared to lutein, zeaxanthin or lutein + zeaxanthin treatments and the level remained, even when challenged by $\mathrm{H}_{2} \mathrm{O}_{2}$. However, $\mathrm{H}_{2} \mathrm{O}_{2}$

zeaxanthin (1:1) at different concentrations and then 1-h exposure with or without $600 \mu \mathrm{M} \mathrm{H}_{2} \mathrm{O}_{2}$. **p $<0.01$ vs control $(0 \mu \mathrm{M})$ without $\mathrm{H}_{2} \mathrm{O}_{2}$; e $24 \mathrm{~h}$ treatment with lutein $(10 \mu \mathrm{M})$ plus zeaxanthin $(10 \mu \mathrm{M})$ with DHA $12.5 \mu \mathrm{M}$ or $25 \mu \mathrm{M}$ and then 1-h exposure with or without $600 \mu \mathrm{M} \mathrm{H}_{2} \mathrm{O}_{2}$. All values are expressed as mean (S.D.)

challenge significantly reduced DHA levels with all the treatments (Table 1). 
Table 1 Fatty acid profile of RPE cells with or without $\mathrm{H}_{2} \mathrm{O}_{2}$ challenge after lutein, zeaxanthin and DHA treatments

\begin{tabular}{|c|c|c|c|c|c|c|c|}
\hline & & Control & Lutein (L) & Zeaxanthin $(\mathrm{Z})$ & DHA (D) & $\mathrm{L}+\mathrm{Z}$ & $\mathrm{L}+\mathrm{Z}+\mathrm{D}$ \\
\hline \multicolumn{8}{|c|}{ Omega-9 monounsaturated fatty acids (MUFAs) } \\
\hline \multirow[t]{2}{*}{ Oleic acid } & $-\mathrm{H}_{2} \mathrm{O}_{2}$ & $57.76(6.35)^{\mathrm{a}}$ & $54.43(7.45)^{a}$ & $56.53(7.21)^{\mathrm{a}}$ & $55.76(6.52)^{\mathrm{a}}$ & $53.27(3.93)^{\mathrm{a}}$ & $54.33(6.45)^{\mathrm{a}}$ \\
\hline & $+\mathrm{H}_{2} \mathrm{O}_{2}$ & $56.23(9.00)^{\mathrm{A}}$ & $54.77(6.55)^{\mathrm{A}}$ & $54.72(4.95)^{\mathrm{A}}$ & $57.59(5.51)^{\mathrm{A}}$ & $60.01(6.52)^{\mathrm{A}}$ & $53.33(5.47)^{\mathrm{A}}$ \\
\hline \multicolumn{8}{|c|}{ Omega-6 polyunsaturated fatty acids ( $n-6$ PUFAs) } \\
\hline \multirow[t]{2}{*}{ Linoleic acid } & $-\mathrm{H}_{2} \mathrm{O}_{2}$ & $15.67(3.35)^{\mathrm{a}}$ & $15.20(2.51)^{\mathrm{a}}$ & $14.65(2.10)^{\mathrm{a}}$ & $15.39(1.93)^{\mathrm{a}}$ & $11.92(0.36)^{\mathrm{a}}$ & $15.58(1.67)^{\mathrm{a}}$ \\
\hline & $+\mathrm{H}_{2} \mathrm{O}_{2}$ & $16.44(5.55)^{\mathrm{AB}}$ & $13.06(2.39)^{\mathrm{A}}$ & $18.52(5.75)^{\mathrm{B}}$ & $16.53(2.88)^{\mathrm{AB}}$ & $14.10(2.86)^{\mathrm{AB}}$ & $17.64(1.63)^{\mathrm{AB}}$ \\
\hline \multirow[t]{2}{*}{ Arachidonic acid } & $-\mathrm{H}_{2} \mathrm{O}_{2}$ & $25.21(3.64)^{\mathrm{a}}$ & $24.39(2.73)^{\mathrm{a}}$ & $25.19(2.68)^{\mathrm{a}}$ & $24.64(3.14)^{\mathrm{a}}$ & $24.76(3.40)^{\mathrm{a}}$ & $24.21(2.79)^{\mathrm{a}}$ \\
\hline & $+\mathrm{H}_{2} \mathrm{O}_{2}$ & $23.04(1.54)^{\mathrm{A}}$ & $24.16(2.25)^{\mathrm{A}}$ & $22.39(1.05)^{\mathrm{A}}$ & $23.76(2.60)^{\mathrm{A}}$ & $24.03(1.36)^{\mathrm{A}}$ & $23.79(1.97)^{\mathrm{A}}$ \\
\hline \multirow[t]{2}{*}{ Adrenic acid } & $-\mathrm{H}_{2} \mathrm{O}_{2}$ & $5.40(0.79)^{\mathrm{a}}$ & $5.20(0.65)^{\mathrm{a}}$ & $5.54(0.96)^{\mathrm{a}}$ & $4.59(0.48)^{\mathrm{a}}$ & $4.67(0.86)^{\mathrm{a}}$ & $4.72(0.83)^{\mathrm{a}}$ \\
\hline & $+\mathrm{H}_{2} \mathrm{O}_{2}$ & $4.96(0.80)^{\mathrm{A}}$ & $5.12(0.78)^{\mathrm{A}}$ & $6.07(0.52)^{\mathrm{A}}$ & $5.90(0.65)^{\mathrm{A}}$ & $5.30(0.89)^{\mathrm{A}}$ & $5.31(0.77)^{\mathrm{A}}$ \\
\hline \multicolumn{8}{|c|}{ Omega-3 polyunsaturated fatty acids ( $n-3$ PUFAs) } \\
\hline \multirow[t]{2}{*}{$\alpha$-Linolenic acid } & $-\mathrm{H}_{2} \mathrm{O}_{2}$ & $10.15(1.49)^{\mathrm{a}}$ & $10.07(2.46)^{\mathrm{a}}$ & $9.05(0.54)^{\mathrm{a}}$ & $8.97(2.92)^{\mathrm{a}}$ & $8.25(0.85)^{\mathrm{a}}$ & $8.48(2.52)^{\mathrm{a}}$ \\
\hline & $+\mathrm{H}_{2} \mathrm{O}_{2}$ & $9.91(1.12)^{\mathrm{A}}$ & $10.47(2.53)^{\mathrm{A}}$ & $9.18(0.49)^{\mathrm{A}}$ & $9.01(2.39)^{\mathrm{A}}$ & $8.61(2.46)^{\mathrm{A}}$ & $9.48(1.61)^{\mathrm{A}}$ \\
\hline \multirow[t]{2}{*}{ Eicosapentaenoic acid } & $-\mathrm{H}_{2} \mathrm{O}_{2}$ & $33.40(2.78)^{\mathrm{ac}}$ & $24.26(8.69)^{\mathrm{b}}$ & $27.22(3.02)^{\mathrm{ab}}$ & $39.72(6.17)^{\mathrm{c}}$ & $25.88(3.79)^{\mathrm{ab}}$ & $35.22(3.39)^{\mathrm{c}}$ \\
\hline & $+\mathrm{H}_{2} \mathrm{O}_{2}$ & $33.78(4.89)^{\mathrm{AC}}$ & $27.23(5.00)^{\mathrm{AB}}$ & $25.14(3.99)^{\mathrm{B}}$ & $40.23(8.12)^{\mathrm{C}}$ & $25.85(3.29)^{\mathrm{AB}}$ & $36.43(3.31)^{\mathrm{C}}$ \\
\hline \multirow[t]{2}{*}{ Docosapentaenoic acid } & $-\mathrm{H}_{2} \mathrm{O}_{2}$ & $4.43(1.28)^{\mathrm{ac}}$ & $4.68(1.02)^{\mathrm{ac}}$ & $3.49(0.63)^{\mathrm{a}}$ & $7.88(0.80)^{\mathrm{b}}$ & $4.71(1.38)^{\mathrm{ac}}$ & $5.82(1.94)^{\mathrm{c}}$ \\
\hline & $+\mathrm{H}_{2} \mathrm{O}_{2}$ & $4.10(0.73)^{\mathrm{AC}}$ & $3.80(1.23)^{\mathrm{AC}}$ & $3.04(0.37)^{\mathrm{A}}$ & $6.93(1.02)^{\mathrm{BC}}$ & $3.63(1.19)^{\mathrm{AC}}$ & $5.18(0.59)^{\mathrm{C}}$ \\
\hline \multirow[t]{2}{*}{ Docosahexaenoic acid } & $-\mathrm{H}_{2} \mathrm{O}_{2}$ & $42.14(3.37)^{\mathrm{a}}$ & $40.49(5.70)^{\mathrm{a}}$ & $38.61(5.66)^{\mathrm{a}}$ & $59.42(4.11)^{\mathrm{b}}$ & $40.00(4.23)^{\mathrm{a}}$ & $64.53(6.23)^{\mathrm{b}}$ \\
\hline & $+\mathrm{H}_{2} \mathrm{O}_{2}$ & $27.52(3.84)^{\mathrm{A}, *}$ & $30.96(2.94)^{\mathrm{A}, *}$ & $27.41(1.61)^{\mathrm{A}, *}$ & $40.75(5.15)^{\mathrm{B}, *}$ & $30.68(5.71)^{\mathrm{A}, *}$ & $45.47(9.77)^{\mathrm{B}, *}$ \\
\hline
\end{tabular}

Values expressed in mean (S.D.) $n g /$ million cells, $n=6$. Treatment concentrations were $10 \mu \mathrm{M}$ lutein, $10 \mu \mathrm{M}$ zeaxanthin and $25 \mu \mathrm{M}$ DHA. Different lowercase alphabets indicate statistical differences between treatment groups without hydrogen peroxide $\left(\mathrm{H}_{2} \mathrm{O}_{2}\right)$ challenge; different uppercase alphabets indicate statistical differences between treatment groups with $\mathrm{H}_{2} \mathrm{O}_{2}$ challenge

$* \mathrm{p}<0.05$ statistical significance with vs without $600 \mu \mathrm{M} \mathrm{H}_{2} \mathrm{O}_{2}$

\section{Combination of Lutein + Zeaxanthin Reduced Omega-6 PUFA Oxidation and DHA Showed Homeo- static Control by Inducing Enzymatic Omega-3 PUFA Oxidation in the ROS-Stressed Cells}

The generation of omega-6 PUFA oxidized products were limited by the carotenoids treatments with or without DHA in non-stressed cells. Surprisingly, 7-dihomo- $\mathrm{F}_{2 \mathrm{t}}$-IsoP level was elevated by lutein (Table 2, Fig. A3 in Online Appendix) while lutein + zeaxanthin reduced it but not with DHA in the non-stressed cells compared to control. Treatment of DHA alone reduced 15-HETE level while lutein + zeaxanthin reduced 20-HETE and elevated 8-HETE levels in the non-stressed cells compared to control.

Exposure of $\mathrm{H}_{2} \mathrm{O}_{2}$ elevated all the oxidized products of ARA and DPA whereas only one product (7-dihomo- $\mathrm{F}_{2 t^{-}}$ IsoP) from AdA was elevated. Single treatment of lutein to the $\mathrm{H}_{2} \mathrm{O}_{2}$-stressed cells reduced 9- and 20-HETE levels compared to control whereas zeaxanthin only reduced 8- and 12-HETE levels. DHA treatment decreased $15-\mathrm{F}_{2 \mathrm{t}^{-}}$ IsoP, 12-HETE and 4-F $3 \mathrm{~F}$-IsoP levels but increased $\mathrm{PGF}_{2 \alpha}$ of the $\mathrm{H}_{2} \mathrm{O}_{2}$-stressed cells compared to control. When the $\mathrm{H}_{2} \mathrm{O}_{2}$-stressed cells were treated with lutein + zeaxanthin, levels of 5- $\mathrm{F}_{2 \mathrm{t}}$-IsoP, 15- $\mathrm{F}_{2 \mathrm{t}}$-IsoP, 5-, 9- and 20-HETE were reduced and remained at similar levels even when DHA was added (Table 2, Fig. A3 in Online Appendix). The level of $4-\mathrm{F}_{3 \mathrm{t}}$-IsoP was also lower in the $\mathrm{H}_{2} \mathrm{O}_{2}$-stressed cells compared to the control when treated with lutein + zeaxanthin with or without DHA. HNE levels were elevated in $\mathrm{H}_{2} \mathrm{O}_{2}$-stressed cells and were unaffected by all the treatments.

Interestingly, when lutein and zexanthin was added separately, 17-HDHA level was reduced in the non-stressed cells compared to control (Table 3, Fig. A4 in Online Appendix). However, DHA alone elevated RvD1, NPD1, 7-HDHA and $14-\mathrm{F}_{3 \mathrm{t}}$-IsoP levels. When the non-stressed cells were treated with lutein + zeaxanthin, $8-\mathrm{F}_{3 \mathrm{t}}-\mathrm{IsoP}$ and $10-\mathrm{F}_{4 \mathrm{t}}-\mathrm{NeuroP}$ levels were elevated while NPD1, 17-HDHA and $14-\mathrm{F}_{3 \mathrm{t}}$-IsoP were reduced. Adding DHA to lutein + zeaxanthin enhanced RvD1, NPD1 and 4-, 8-, 11- and 17-HDHA levels while $14-\mathrm{F}_{3 \mathrm{t}}$-IsoP level was reduced compared to control.

The challenge of $\mathrm{H}_{2} \mathrm{O}_{2}$ enhanced omega- 3 PUFA oxidation (Table 3, Fig. A4 in Online Appendix) where levels of 5- $\mathrm{F}_{3 \mathrm{t}}$-IsoP, 4-, 10- and 20- $\mathrm{F}_{4 \mathrm{t}}-\mathrm{NeuroP}, 7-$, 8-, 14-, 17-HDHA, $14-\mathrm{F}_{3 \mathrm{t}}$-IsoP and HHE were induced compared to control. Single treatment of lutein reduced $4-\mathrm{F}_{4 \mathrm{t}}-\mathrm{NeuroP}, 17-\mathrm{HDHA}$ and $14-\mathrm{F}_{3 \mathrm{t}}$-IsoP levels while zeaxanthin alone reduced $5-\mathrm{F}_{3 \mathrm{t}}{ }^{-}$ and $18-\mathrm{F}_{3 \mathrm{t}}-\mathrm{IsoP}, 4-\mathrm{F}_{4 \mathrm{t}}-\mathrm{NeuroP}, 14-$ and 17-HDHA, 14- $\mathrm{F}_{3 \mathrm{t}^{-}}$ IsoP and $\mathrm{HHE}$ levels in the $\mathrm{H}_{2} \mathrm{O}_{2}$-stressed cells compared to control. However, DHA treatment elevated $8-\mathrm{F}_{3 \mathrm{t}}$-IsoP, 
Table 2 Lipid oxidation products of omega-6 PUFAs measured in RPE cells with or without $\mathrm{H}_{2} \mathrm{O}_{2}$ challenge after lutein, zeaxanthin and DHA treatments

\begin{tabular}{|c|c|c|c|c|c|c|c|}
\hline & & Control & Lutein $(\mathrm{L})$ & Zeaxanthin $(\mathrm{Z})$ & DHA (D) & $\mathrm{L}+\mathrm{Z}$ & $\mathrm{L}+\mathrm{Z}+\mathrm{D}$ \\
\hline \multicolumn{8}{|c|}{ Arachidonic acid derived } \\
\hline \multirow[t]{2}{*}{$5-\mathrm{F}_{2 \mathrm{t}}$-IsoP } & $-\mathrm{H}_{2} \mathrm{O}_{2}$ & $5.61(1.80)^{\mathrm{a}}$ & $4.46(1.90)^{\mathrm{a}}$ & $4.78(2.01)^{\mathrm{a}}$ & $6.85(1.97)^{\mathrm{a}}$ & $4.29(0.81)^{\mathrm{a}}$ & $5.19(0.66)^{\mathrm{a}}$ \\
\hline & $+\mathrm{H}_{2} \mathrm{O}_{2}$ & $15.90(2.06)^{\mathrm{A}, *}$ & $13.38(2.31)^{\mathrm{A}, *}$ & $13.71(3.68)^{\mathrm{A},{ }^{*}}$ & $13.62(2.33)^{\mathrm{A}, *}$ & $7.44(1.71)^{\mathrm{B}, *}$ & $7.53(0.96)^{B}$ \\
\hline \multirow[t]{2}{*}{$15-\mathrm{F}_{2 \mathrm{t}}$-IsoP } & $-\mathrm{H}_{2} \mathrm{O}_{2}$ & $0.57(0.15)^{\mathrm{a}}$ & $0.54(0.09)^{\mathrm{a}}$ & $0.43(0.13)^{\mathrm{a}}$ & $0.46(0.18)^{\mathrm{a}}$ & $0.43(0.18)^{\mathrm{a}}$ & $0.48(0.25)^{\mathrm{a}}$ \\
\hline & $+\mathrm{H}_{2} \mathrm{O}_{2}$ & $1.52(0.26)^{\mathrm{A}, *}$ & $1.16(0.40)^{\mathrm{AB}, *}$ & $1.14(0.28)^{\mathrm{AB}, *}$ & $0.92(0.32)^{\mathrm{BC}, *}$ & $0.75(0.29)^{\mathrm{BC}}$ & $0.69(0.40)^{\mathrm{C}}$ \\
\hline \multirow[t]{2}{*}{$\mathrm{PGF}_{2 \alpha}$} & $-\mathrm{H}_{2} \mathrm{O}_{2}$ & $1.48(0.43)^{\mathrm{a}}$ & $1.07(0.51)^{\mathrm{a}}$ & $1.33(0.13)^{\mathrm{a}}$ & $1.84(0.77)^{\mathrm{a}}$ & $1.43(0.13)^{\mathrm{a}}$ & $1.31(0.08)^{\mathrm{a}}$ \\
\hline & $+\mathrm{H}_{2} \mathrm{O}_{2}$ & $2.13(0.89)^{\mathrm{AB}}$ & $1.97(1.18)^{\mathrm{AB}}$ & $1.43(0.22)^{\mathrm{A}}$ & $2.96(0.99)^{\mathrm{B}}$ & $1.53(0.27)^{\mathrm{A}}$ & $1.40(0.21)^{\mathrm{A}}$ \\
\hline \multirow[t]{2}{*}{ 5-HETE } & $-\mathrm{H}_{2} \mathrm{O}_{2}$ & $0.73(0.35)^{\mathrm{a}}$ & $0.84(0.45)^{\mathrm{a}}$ & $0.87(0.15)^{\mathrm{a}}$ & $1.28(0.47)^{\mathrm{a}}$ & $0.74(0.27)^{\mathrm{a}}$ & $0.32(0.14)^{\mathrm{a}}$ \\
\hline & $+\mathrm{H}_{2} \mathrm{O}_{2}$ & $1.54(0.46)^{\mathrm{ABC}}$ & $1.31(0.61)^{\mathrm{AC}}$ & $1.76(1.22)^{\mathrm{AB}}$ & $2.50(1.38)^{\mathrm{B}, *}$ & $0.57(0.08)^{\mathrm{C}}$ & $0.66(0.36)^{\mathrm{C}}$ \\
\hline \multirow[t]{2}{*}{ 8-HETE } & $-\mathrm{H}_{2} \mathrm{O}_{2}$ & $0.75(0.31)^{\mathrm{ab}}$ & $0.64(0.22)^{\mathrm{ab}}$ & $0.59(0.24)^{\mathrm{a}}$ & $0.91(0.27)^{\mathrm{ab}}$ & $1.55(0.52)^{\mathrm{b}}$ & $0.64(0.15)^{\mathrm{ab}}$ \\
\hline & $+\mathrm{H}_{2} \mathrm{O}_{2}$ & $2.06(1.02)^{\mathrm{A}, *}$ & $1.74(0.50)^{\mathrm{AB}, *}$ & $1.07(0.53)^{\mathrm{B}}$ & $1.58(0.94)^{\mathrm{AB}, *}$ & $2.14(0.48)^{\mathrm{A}}$ & $1.72(0.44)^{\mathrm{AB}}$ \\
\hline \multirow[t]{2}{*}{ 9-HETE } & $-\mathrm{H}_{2} \mathrm{O}_{2}$ & $2.08(0.98)^{\mathrm{a}}$ & $1.07(0.37)^{\mathrm{a}}$ & $1.92(0.43)^{\mathrm{a}}$ & $2.45(1.34)^{\mathrm{a}}$ & $1.63(0.17)^{\mathrm{a}}$ & $1.59(0.43)^{\mathrm{a}}$ \\
\hline & $+\mathrm{H}_{2} \mathrm{O}_{2}$ & $4.82(1.68)^{\mathrm{A}, *}$ & $2.57(1.36)^{\mathrm{B}}$ & $4.82(1.51)^{\mathrm{A}, *}$ & $6.03(2.26)^{\mathrm{A}, *}$ & $1.31(0.14)^{\mathrm{B}}$ & $1.60(0.36)^{\mathrm{B}}$ \\
\hline \multirow[t]{2}{*}{ 11-HETE } & $-\mathrm{H}_{2} \mathrm{O}_{2}$ & $0.78(0.35)^{\mathrm{a}}$ & $0.58(0.21)^{\mathrm{a}}$ & $0.41(0.15)^{\mathrm{a}}$ & $0.47(0.27)^{\mathrm{a}}$ & $0.31(0.13)^{\mathrm{a}}$ & $0.59(0.30)^{\mathrm{a}}$ \\
\hline & $+\mathrm{H}_{2} \mathrm{O}_{2}$ & $1.54(0.68)^{\mathrm{A}, *}$ & $0.97(0.65)^{\mathrm{A}, *}$ & $1.57(0.65)^{\mathrm{A}, *}$ & $1.52(0.32)^{\mathrm{A}, *}$ & $1.24(0.05)^{\mathrm{A}, *}$ & $1.39(0.24)^{\mathrm{A}, *}$ \\
\hline \multirow[t]{2}{*}{ 12-HETE } & $-\mathrm{H}_{2} \mathrm{O}_{2}$ & $1.64(0.27)^{\mathrm{a}}$ & $1.54(0.20)^{\mathrm{a}}$ & $1.37(0.42)^{\mathrm{a}}$ & $1.32(1.13)^{\mathrm{a}}$ & $1.26(0.10)^{\mathrm{a}}$ & $1.40(0.30)^{\mathrm{a}}$ \\
\hline & $+\mathrm{H}_{2} \mathrm{O}_{2}$ & $3.35(0.83)^{\mathrm{A}, *}$ & $2.35(0.85)^{\mathrm{B}}$ & $1.84(0.45)^{\mathrm{BC}}$ & $1.80(0.86)^{\mathrm{BC}}$ & $1.33(0.32)^{\mathrm{C}}$ & $1.38(0.14)^{\mathrm{BC}}$ \\
\hline \multirow[t]{2}{*}{ 15-HETE } & $-\mathrm{H}_{2} \mathrm{O}_{2}$ & $5.48(0.78)^{\mathrm{ab}}$ & $5.82(0.83)^{\mathrm{a}}$ & $5.78(0.50)^{\mathrm{a}}$ & $4.06(0.91)^{\mathrm{b}}$ & $4.72(0.91)^{\mathrm{ab}}$ & $4.16(0.58)^{\mathrm{b}}$ \\
\hline & $+\mathrm{H}_{2} \mathrm{O}_{2}$ & $5.14(1.15)^{\mathrm{A}}$ & $5.13(0.96)^{\mathrm{A}}$ & $5.56(1.25)^{\mathrm{A}}$ & $5.40(1.09)^{\mathrm{A}, *}$ & $4.12(0.40)^{\mathrm{A}}$ & $4.25(0.23)^{\mathrm{A}}$ \\
\hline \multirow[t]{2}{*}{ 20-HETE } & $-\mathrm{H}_{2} \mathrm{O}_{2}$ & $3.24(0.99)^{\mathrm{ab}}$ & $2.52(0.86)^{\mathrm{ab}}$ & $2.64(0.43)^{\mathrm{ab}}$ & $3.88(0.92)^{\mathrm{a}}$ & $1.87(0.41)^{\mathrm{b}}$ & $3.00(0.49)^{\mathrm{ab}}$ \\
\hline & $+\mathrm{H}_{2} \mathrm{O}_{2}$ & $5.78(0.82)^{\mathrm{A}, *}$ & $5.30(0.90)^{\mathrm{AB}, *}$ & $4.97(1.01)^{\mathrm{ABC}, *}$ & $6.02(0.87)^{\mathrm{A}, *}$ & $3.93(0.94)^{\mathrm{BC}, *}$ & $3.54(1.20)^{\mathrm{C}}$ \\
\hline \multicolumn{8}{|l|}{ Adrenic acid derived } \\
\hline \multirow[t]{2}{*}{ 7-Dihomo- $\mathrm{F}_{2 \mathrm{t}}$-IsoP } & $-\mathrm{H}_{2} \mathrm{O}_{2}$ & $5.71(1.65)^{\mathrm{ab}}$ & $8.26(1.82)^{\mathrm{b}}$ & $7.40(2.06)^{\mathrm{ab}}$ & $6.50(2.35)^{\mathrm{ab}}$ & $4.67(2.10)^{\mathrm{ac}}$ & $2.72(1.19)^{\mathrm{c}}$ \\
\hline & $+\mathrm{H}_{2} \mathrm{O}_{2}$ & $15.13(1.23)^{\mathrm{AB}, *}$ & $15.50(1.65)^{\mathrm{B}, *}$ & $14.23(1.36)^{\mathrm{AB}, *}$ & $13.20(2.54)^{\mathrm{AB}, *}$ & $13.48(1.14)^{\mathrm{A}, *}$ & $12.40(1.36)^{\mathrm{AB}, *}$ \\
\hline \multirow[t]{2}{*}{ 17-Dihomo- $\mathrm{F}_{2 \mathrm{t}}$-IsoP } & $-\mathrm{H}_{2} \mathrm{O}_{2}$ & $0.67(0.35)^{\mathrm{a}}$ & $0.58(0.22)^{\mathrm{a}}$ & $0.62(0.32)^{\mathrm{a}}$ & $0.85(0.58)^{\mathrm{a}}$ & $0.82(0.48)^{\mathrm{a}}$ & $0.72(0.24)^{\mathrm{a}}$ \\
\hline & $+\mathrm{H}_{2} \mathrm{O}_{2}$ & $0.78(0.37)^{\mathrm{A}}$ & $0.66(0.33)^{\mathrm{A}}$ & $0.91(0.58)^{\mathrm{A}}$ & $0.96(0.85)^{\mathrm{A}}$ & $0.76(0.37)^{\mathrm{A}}$ & $1.04(0.54)^{\mathrm{A}}$ \\
\hline \multirow[t]{2}{*}{ 7-Dihomo- $\mathrm{F}_{2 \mathrm{t}}$-IsoF } & $-\mathrm{H}_{2} \mathrm{O}_{2}$ & $8.42(3.39)^{\mathrm{a}}$ & $8.24(4.73)^{\mathrm{a}}$ & $8.71(5.36)^{\mathrm{a}}$ & $6.96(3.28)^{\mathrm{a}}$ & $7.21(3.34)^{\mathrm{a}}$ & $8.32(3.47)^{\mathrm{a}}$ \\
\hline & $+\mathrm{H}_{2} \mathrm{O}_{2}$ & $5.69(4.88)^{\mathrm{A}}$ & $5.07(3.70)^{\mathrm{A}}$ & $5.61(5.34)^{\mathrm{A}}$ & $5.99(4.19)^{\mathrm{A}}$ & $6.11(4.16)^{\mathrm{A}}$ & $6.56(4.48)^{\mathrm{A}}$ \\
\hline \multirow[t]{2}{*}{ 17-Dihomo- $\mathrm{F}_{2 \mathrm{t}}$-IsoF } & $-\mathrm{H}_{2} \mathrm{O}_{2}$ & $1.54(0.87)^{\mathrm{a}}$ & $2.11(1.88)^{\mathrm{a}}$ & $2.21(1.73)^{\mathrm{a}}$ & $2.54(3.01)^{\mathrm{a}}$ & $2.31(2.55)^{\mathrm{a}}$ & $2.73(2.66)^{\mathrm{a}}$ \\
\hline & $+\mathrm{H}_{2} \mathrm{O}_{2}$ & $1.66(2.32)^{\mathrm{A}}$ & $1.99(2.64)^{\mathrm{A}}$ & $1.65(2.26)^{\mathrm{A}}$ & $1.39(1.73)^{\mathrm{A}}$ & $1.40(1.44)^{\mathrm{A}}$ & $2.00(2.79)^{\mathrm{A}}$ \\
\hline \multicolumn{8}{|c|}{ Omega-6 Docosapentaenoic acid derived } \\
\hline \multirow[t]{2}{*}{$4-\mathrm{F}_{3 \mathrm{t}}$-IsoP } & $-\mathrm{H}_{2} \mathrm{O}_{2}$ & $1.16(0.50)^{\mathrm{a}}$ & $1.92(0.68)^{\mathrm{a}}$ & $1.61(0.51)^{\mathrm{a}}$ & $1.42(0.45)^{\mathrm{a}}$ & $1.62(0.40)^{\mathrm{a}}$ & $0.88(0.33)^{\mathrm{a}}$ \\
\hline & $+\mathrm{H}_{2} \mathrm{O}_{2}$ & $3.94(1.48)^{\mathrm{A}, *}$ & $3.41(0.87)^{\mathrm{AB}, *}$ & $3.24(1.20)^{\mathrm{AB}, *}$ & $2.36(0.39)^{\mathrm{B}}$ & $2.85(0.70)^{\mathrm{A}, *}$ & $1.79(0.90)^{\mathrm{C}}$ \\
\hline \multicolumn{8}{|c|}{ Peroxidation end-product } \\
\hline \multirow[t]{2}{*}{ 4-HNE } & $-\mathrm{H}_{2} \mathrm{O}_{2}$ & $5.94(1.19)^{\mathrm{a}}$ & $6.69(1.13)^{\mathrm{a}}$ & $6.83(1.48)^{\mathrm{a}}$ & $5.92(1.28)^{\mathrm{a}}$ & $6.42(0.99)^{\mathrm{a}}$ & $6.63(0.71)^{\mathrm{a}}$ \\
\hline & $+\mathrm{H}_{2} \mathrm{O}_{2}$ & $8.77(1.96)^{\mathrm{A}, *}$ & $9.03(1.46)^{\mathrm{A}, *}$ & $8.37(0.81)^{\mathrm{A}, *}$ & $8.47(0.71)^{\mathrm{A}, *}$ & $8.59(0.45)^{\mathrm{A}, *}$ & $9.18(0.61)^{\mathrm{A}, *}$ \\
\hline
\end{tabular}

Values expressed in mean (S.D.) ng/million cells, $n=6$. Treatment concentrations were $10 \mu \mathrm{M}$ lutein, $10 \mu \mathrm{M}$ zeaxanthin and $25 \mu \mathrm{M}$ DHA. Different lower-case alphabets indicate statistical differences between treatment groups without hydrogen peroxide $\left(\mathrm{H}_{2} \mathrm{O}_{2}\right)$ challenge; different uppercase capitals indicate statistical differences between treatment groups with $\mathrm{H}_{2} \mathrm{O}_{2}$ challenge

$*_{\mathrm{p}}<0.05$ statistical significance with vs without $600 \mu \mathrm{M} \mathrm{H}_{2} \mathrm{O}_{2}$

10- $\mathrm{F}_{4 \mathrm{t}}$-NeuroP, 4-, 7- and 11-HDHA and NPD1 levels but reduced $4-\mathrm{F}_{4 \mathrm{t}}-\mathrm{NeuroP}$ and $14-\mathrm{F}_{3 \mathrm{t}}$-IsoP levels compared to control. It was surprising to observe numerous amounts of omega- 3 PUFA oxidized products to be reduced by lutein + zeaxanthin namely, $18-\mathrm{F}_{3 \mathrm{t}}-\mathrm{IsoP}$, 4-and $20-\mathrm{F}_{4 \mathrm{t}}-\mathrm{Neu}-$ roP, 8-, 11- and 17-HDHA, NPD1, 14- F $_{3 \mathrm{t}}$-IsoP and HHE levels in the $\mathrm{H}_{2} \mathrm{O}_{2}$-stressed cells compared to control while only $8-\mathrm{F}_{3 \mathrm{t}}$-IsoP level was elevated. The addition of DHA to lutein + zeaxanthin did not further reduce the levels of $18-\mathrm{F}_{3 \mathrm{t}}$-IsoP, 4- and $20-\mathrm{F}_{4 \mathrm{t}}$-NeuroP, $14-\mathrm{F}_{3 \mathrm{t}}$-IsoP and HHE but it elevated RvE1, RvD1, NPD1 and 4-, 7-, 8- and 11-HDHA levels. 
Table 3 Lipid oxidation products of omega-3 PUFAs measured in RPE cells with or without $\mathrm{H}_{2} \mathrm{O}_{2}$ challenge after lutein, zeaxanthin and DHA treatments

\begin{tabular}{|c|c|c|c|c|c|c|c|c|}
\hline & & Control & & Lutein $(\mathrm{L})$ & Zeaxanthin (Z) & DHA (D) & $\mathrm{L}+\mathrm{Z}$ & $\mathrm{L}+\mathrm{Z}+\mathrm{D}$ \\
\hline \multicolumn{9}{|c|}{ Eicosapentaenoic acid derived } \\
\hline \multirow[t]{2}{*}{$5-\mathrm{F}_{3 \mathrm{t}}$-IsoP } & $-\mathrm{H}_{2} \mathrm{O}_{2}$ & $3.39(0.74)^{\mathrm{a}}$ & $3.05(1.23)^{\mathrm{a}}$ & & $0.93(0.59)^{\mathrm{a}}$ & $2.78(0.88)^{\mathrm{a}}$ & $1.45(1.02)^{\mathrm{a}}$ & $1.90(0.84)^{\mathrm{a}}$ \\
\hline & $+\mathrm{H}_{2} \mathrm{O}_{2}$ & $6.16(1.29)^{\mathrm{AC}, *}$ & $6.12(1.84)^{\mathrm{AC}, *}$ & & $2.45(0.52)^{\mathrm{B}}$ & $5.18(0.90)^{\mathrm{AC}, *}$ & $5.81(3.24)^{\mathrm{C}, *}$ & $6.16(1.97)^{\mathrm{C}, *}$ \\
\hline \multirow[t]{2}{*}{$8-\mathrm{F}_{3 \mathrm{t}}$-IsoP } & $-\mathrm{H}_{2} \mathrm{O}_{2}$ & $1.06(0.40)^{\mathrm{a}}$ & $1.29(0.48)^{\mathrm{ab}}$ & & $0.84(0.14)^{\mathrm{a}}$ & $1.62(0.44)^{\mathrm{ab}}$ & $2.12(0.84)^{b}$ & $1.67(0.27)^{\mathrm{a}}$ \\
\hline & $+\mathrm{H}_{2} \mathrm{O}_{2}$ & $1.69(0.75)^{\mathrm{A}}$ & $2.15(0.37)^{\mathrm{AB}, *}$ & & $1.12(0.35)^{\mathrm{A}}$ & $2.46(0.80)^{\mathrm{B},{ }^{*}}$ & $3.63(0.36)^{\mathrm{C},{ }^{*}}$ & $2.89(0.63)^{\mathrm{BC}, *}$ \\
\hline \multirow[t]{2}{*}{$18-\mathrm{F}_{3 \mathrm{t}}$-IsoP } & $-\mathrm{H}_{2} \mathrm{O}_{2}$ & $1.83(0.83)^{\mathrm{a}}$ & $2.12(0.80)^{\mathrm{a}}$ & & $1.65(0.20)^{\mathrm{a}}$ & $2.21(1.04)^{\mathrm{a}}$ & $1.19(0.61)^{\mathrm{a}}$ & $1.07(0.23)^{\mathrm{a}}$ \\
\hline & $+\mathrm{H}_{2} \mathrm{O}_{2}$ & $4.50(2.63)^{\mathrm{A}}$ & $4.05(1.06)^{\mathrm{A}}$ & & $2.14(0.68)^{\mathrm{BC}}$ & $3.80(1.46)^{\mathrm{AB}}$ & $1.10(0.32)^{\mathrm{C}}$ & $0.90(0.42)^{\mathrm{C}}$ \\
\hline RvE1 & $+\mathrm{H}_{2} \mathrm{O}_{2}$ & $1.39(0.16)^{\mathrm{A}}$ & $1.51(0.39)^{\mathrm{A}}$ & & $1.31(0.06)^{\mathrm{A}}$ & $1.74(0.44)^{\mathrm{A}}$ & $1.41(0.29)^{\mathrm{A}}$ & $2.25(0.52)^{\mathrm{B}, *}$ \\
\hline \multicolumn{9}{|c|}{ Docosahexaenoic acid derived } \\
\hline \multirow[t]{2}{*}{$4-\mathrm{F}_{4 \mathrm{t}}$-NeuroP } & $-\mathrm{H}_{2} \mathrm{O}_{2}$ & $3.05(1.15)^{\mathrm{a}}$ & $2.31(0.86)^{\mathrm{a}}$ & & $2.34(1.02)^{\mathrm{a}}$ & $2.72(0.76)^{\mathrm{a}}$ & $1.86(0.39)^{\mathrm{a}}$ & $1.38(0.27)^{\mathrm{a}}$ \\
\hline & $+\mathrm{H}_{2} \mathrm{O}_{2}$ & $8.43(1.09)^{\mathrm{A}, *}$ & $5.36(1.21)^{\mathrm{B}, *}$ & & $4.99(1.14)^{\mathrm{B},{ }^{*}}$ & $5.56(1.74)^{\mathrm{B}, *}$ & $2.62(1.40)^{\mathrm{C}}$ & $2.57(1.71)^{\mathrm{C}}$ \\
\hline \multirow[t]{2}{*}{$10-\mathrm{F}_{4 \mathrm{t}}-$ NeuroP } & $-\mathrm{H}_{2} \mathrm{O}_{2}$ & $7.06(2.75)^{\mathrm{a}}$ & $10.97(2.89)^{\mathrm{ab}}$ & & $7.91(2.72)^{\mathrm{ac}}$ & $12.88(1.71)^{\mathrm{bc}}$ & $13.25(1.62)^{\mathrm{b}}$ & $9.32(0.95)^{\mathrm{a}}$ \\
\hline & $+\mathrm{H}_{2} \mathrm{O}_{2}$ & $13.52(2.63)^{\mathrm{A},{ }^{*}}$ & $14.87(3.73)^{\mathrm{A}}$ & & $16.33(3.43)^{\mathrm{AB}, *}$ & $21.54(4.97)^{\mathrm{B}, *}$ & $16.94(3.81)^{\mathrm{AB}}$ & $14.80(3.98)^{\mathrm{A}, *}$ \\
\hline \multirow[t]{2}{*}{$13-\mathrm{F}_{4 \mathrm{t}}-$ NeuroP } & $-\mathrm{H}_{2} \mathrm{O}_{2}$ & $1.10(0.56)^{\mathrm{a}}$ & $2.09(0.78)^{\mathrm{a}}$ & & $1.62(0.24)^{\mathrm{a}}$ & $1.44(0.40)^{\mathrm{a}}$ & $1.79(0.21)^{\mathrm{a}}$ & $1.52(0.24)^{\mathrm{a}}$ \\
\hline & $+\mathrm{H}_{2} \mathrm{O}_{2}$ & $3.08(2.19)^{\mathrm{A}}$ & $3.75(1.89)^{\mathrm{A}}$ & & $3.96(2.89)^{\mathrm{A},{ }^{*}}$ & $4.43(1.28)^{\mathrm{A},{ }^{*}}$ & $2.46(0.70)^{\mathrm{A}}$ & $1.92(0.77)^{\mathrm{A}}$ \\
\hline 14- $\mathrm{F}_{4 \mathrm{t}}$-NeuroP & $+\mathrm{H}_{2} \mathrm{O}_{2}$ & $5.39(3.33)^{\mathrm{AB}}$ & $4.21(2.43)^{\mathrm{AB}}$ & & $2.98(0.51)^{\mathrm{A}}$ & $4.77(1.04)^{\mathrm{AB}}$ & $4.99(1.19)^{\mathrm{AB}}$ & $6.52(2.23)^{\mathrm{B}}$ \\
\hline \multirow[t]{2}{*}{$20-\mathrm{F}_{4 \mathrm{t}}-\mathrm{NeuroP}$} & $-\mathrm{H}_{2} \mathrm{O}_{2}$ & $1.33(0.35)^{\mathrm{a}}$ & $1.73(0.86)^{\mathrm{a}}$ & & $1.52(0.12)^{\mathrm{a}}$ & $2.63(1.36)^{\mathrm{a}}$ & $2.18(0.93)^{\mathrm{a}}$ & $1.34(0.11)^{\mathrm{a}}$ \\
\hline & $+\mathrm{H}_{2} \mathrm{O}_{2}$ & $4.95(2.15)^{\mathrm{A}, *}$ & $3.95(2.38)^{\mathrm{AB}, *}$ & & $1.90(0.54)^{\mathrm{BC}}$ & $4.61(2.14)^{\mathrm{A}}$ & $2.00(0.75)^{\mathrm{BC}}$ & $1.61(0.47)^{\mathrm{C}}$ \\
\hline \multirow[t]{2}{*}{ RvD1 } & $-\mathrm{H}_{2} \mathrm{O}_{2}$ & $1.48(0.17)^{\mathrm{ab}}$ & $1.48(0.19)^{\mathrm{ab}}$ & & $1.13(0.04)^{\mathrm{a}}$ & $1.90(0.18)^{\mathrm{bc}}$ & $1.52(0.20)^{\mathrm{ab}}$ & $2.03(0.58)^{\mathrm{c}}$ \\
\hline & $+\mathrm{H}_{2} \mathrm{O}_{2}$ & $1.51(0.14)^{\mathrm{AB}}$ & $1.45(0.23)^{\mathrm{AB}}$ & & $1.14(0.07)^{\mathrm{A}}$ & $2.59(0.20)^{\mathrm{C}, *}$ & $1.78(0.64)^{\mathrm{B}}$ & $2.42(0.24)^{\mathrm{C}, *}$ \\
\hline \multirow[t]{2}{*}{ NPD1 } & $-\mathrm{H}_{2} \mathrm{O}_{2}$ & $1.79(0.16)^{\mathrm{a}}$ & $1.62(0.19)^{\mathrm{ac}}$ & & $1.61(0.18)^{\mathrm{ac}}$ & $2.40(0.22)^{\mathrm{b}}$ & $1.20(0.07)^{\mathrm{c}}$ & $2.40(0.35)^{\mathrm{b}}$ \\
\hline & $+\mathrm{H}_{2} \mathrm{O}_{2}$ & $1.74(0.34)^{\mathrm{AC}}$ & $1.95(0.32)^{\mathrm{A}}$ & & $1.69(0.35)^{\mathrm{AC}}$ & $3.58(0.32)^{\mathrm{B},{ }^{*}}$ & $1.38(0.10)^{\mathrm{C}}$ & $3.82(0.60)^{\mathrm{B}, *}$ \\
\hline \multirow[t]{2}{*}{ 4-HDHA } & $-\mathrm{H}_{2} \mathrm{O}_{2}$ & $0.92(0.59)^{\mathrm{a}}$ & $0.67(0.10)^{\mathrm{a}}$ & & $0.42(0.17)^{\mathrm{a}}$ & $1.21(0.57)^{\mathrm{a}}$ & $0.68(0.43)^{\mathrm{a}}$ & $2.50(0.66)^{\mathrm{b}}$ \\
\hline & $+\mathrm{H}_{2} \mathrm{O}_{2}$ & $1.46(0.33)^{\mathrm{A}}$ & $0.96(0.49)^{\mathrm{A}}$ & & $0.92(0.44)^{\mathrm{A}}$ & $4.23(1.05)^{\mathrm{B},{ }^{*}}$ & $1.39(0.47)^{\mathrm{A}}$ & $4.26(0.46)^{\mathrm{B}, *}$ \\
\hline \multirow[t]{2}{*}{ 7-HDHA } & $-\mathrm{H}_{2} \mathrm{O}_{2}$ & $1.34(0.24)^{\mathrm{a}}$ & $1.73(0.51)^{\mathrm{ab}}$ & & $1.27(0.16)^{\mathrm{a}}$ & $2.25(0.45)^{\mathrm{bc}}$ & $1.15(0.07)^{\mathrm{a}}$ & $2.11(0.53)^{\mathrm{ac}}$ \\
\hline & $+\mathrm{H}_{2} \mathrm{O}_{2}$ & $2.21(0.26)^{\mathrm{A}, *}$ & $2.89(0.98)^{\mathrm{AB}, *}$ & & $2.39(0.47)^{\mathrm{A},{ }^{*}}$ & $3.71(0.62)^{\mathrm{BC}, *}$ & $1.40(0.15)^{\mathrm{A}}$ & $3.97(0.65)^{\mathrm{C}, *}$ \\
\hline \multirow[t]{2}{*}{ 8-HDHA } & $-\mathrm{H}_{2} \mathrm{O}_{2}$ & $2.25(0.36)^{\mathrm{a}}$ & $1.91(0.11)^{\mathrm{a}}$ & & $2.30(0.40)^{\mathrm{a}}$ & $2.67(0.21)^{\mathrm{a}}$ & $1.65(0.19)^{\mathrm{a}}$ & $3.29(0.69)^{\mathrm{b}}$ \\
\hline & $+\mathrm{H}_{2} \mathrm{O}_{2}$ & $3.41(0.83)^{\mathrm{AC}, *}$ & $4.09(0.48)^{\mathrm{AB}, *}$ & & $3.06(0.57)^{\mathrm{C}}$ & $3.82(0.53)^{\mathrm{ABC}, *}$ & $2.92(0.36)^{\mathrm{C}, *}$ & $4.53(1.13)^{\mathrm{B}, *}$ \\
\hline \multirow[t]{2}{*}{ 11-HDHA } & $-\mathrm{H}_{2} \mathrm{O}_{2}$ & $1.48(0.26)^{\mathrm{a}}$ & $1.42(0.18)^{\mathrm{a}}$ & & $1.52(0.30)^{\mathrm{a}}$ & $1.30(0.14)^{\mathrm{a}}$ & $1.55(0.18)^{\mathrm{a}}$ & $2.27(0.55)^{\mathrm{b}}$ \\
\hline & $+\mathrm{H}_{2} \mathrm{O}_{2}$ & $1.70(0.23)^{\mathrm{AC}}$ & $1.85(0.54)^{\mathrm{AC}}$ & & $1.45(0.43)^{\mathrm{A}}$ & $2.11(0.63)^{\mathrm{C}, *}$ & $1.19(0.07)^{\mathrm{A}}$ & $2.90(0.47)^{\mathrm{B}, *}$ \\
\hline 14-HDHA & $-\mathrm{H}_{2} \mathrm{O}_{2}$ & $2.41(0.22)^{\mathrm{a}}$ & $2.65(0.28)^{\mathrm{a}}$ & & $2.57(0.20)^{\mathrm{a}}$ & $2.53(0.29)^{\mathrm{a}}$ & $2.15(0.05)^{\mathrm{a}}$ & $2.42(0.19)^{\mathrm{a}}$ \\
\hline 17-HDHA & $+\mathrm{H}_{2} \mathrm{O}_{2}$ & $3.84(0.73)^{\mathrm{A},{ }^{*}}$ & $1.99(0.58)^{\mathrm{B}}$ & & $1.61(0.38)^{\mathrm{B}}$ & $3.79(0.69)^{\mathrm{A}}$ & $2.03(0.60)^{\mathrm{B}}$ & $4.52(0.82)^{\mathrm{A}}$ \\
\hline
\end{tabular}




\section{Discussion}

The findings from this study addressed some important functions of lutein + zeaxanthin and DHA in the oxidation pathway of PUFA in RPE cells. Lutein or zeaxanthin or when combined displayed potent antioxidant properties in non-enzymatic oxidation process for both omega- 6 and omega-3 PUFA where consistent decreased levels of isoprostanes (namely $5-\mathrm{F}_{2 \mathrm{t}}$-and $15-\mathrm{F}_{2 \mathrm{t}}$-IsoP and $4-\mathrm{F}_{4 \mathrm{t}}-\mathrm{NeuroP}$ ) and HHE were observed. The incorporation of DHA alone or with lutein + zexanthin to the $\mathrm{H}_{2} \mathrm{O}_{2}$-stressed cells showed homeostatic control where it enhanced enzymatic oxidation and subsequently up-regulated specialized pro-resolving mediators such as RvD1 and NPD1 that potentially compensated the loss of 17-HDHA by lutein and/or zeaxanthin. These observation further supports our recent findings in human study, where poor circulatory lutein + zeaxanthin and DHA are associated to AMD risk in the expense of elevated omega-6 PUFA oxidation and loss of omega-3 PUFA oxidation [35].

The yellow macula is rich in carotenoid pigments mainly, lutein and zeaxanthin. They are suggested to protect the macula from photo-oxidative damage by filtering blue light and act as antioxidant to quench the excited triplet molecules or singlet oxygen that can induce reactive oxygen species (ROS) such as lipid peroxides or superoxide anions [36]. In addition, lutein and zeaxanthin can indirectly protect the RPE by absorbing short-wavelength light; it is normally taken up by lipofuscin, accumulate in the RPE and generate ROS via photosensitization. Moreover, DHA 
Table 4 Cellular gene expression of RPE cell with or without $\mathrm{H}_{2} \mathrm{O}_{2}$ challenge after lutein, zeaxanthin and DHA treatments

\begin{tabular}{|c|c|c|c|c|c|c|c|}
\hline & & Control & Lutein (L) & Zeaxanthin (Z) & DHA (D) & $\mathrm{L}+\mathrm{Z}$ & $\mathrm{L}+\mathrm{Z}+\mathrm{D}$ \\
\hline \multicolumn{8}{|c|}{ Lipid metabolism } \\
\hline \multirow[t]{2}{*}{$\operatorname{PPAR} \alpha$} & $-\mathrm{H}_{2} \mathrm{O}_{2}$ & $1.00(0.26)^{\mathrm{a}}$ & $1.13(0.49)^{\mathrm{a}}$ & $0.96(0.07)^{\mathrm{a}}$ & $1.07(0.34)^{\mathrm{a}}$ & $0.86(0.54)^{\mathrm{a}}$ & $0.82(0.41)^{\mathrm{a}}$ \\
\hline & $+\mathrm{H}_{2} \mathrm{O}_{2}$ & $1.57(0.60)^{\mathrm{A}}$ & $0.90(0.02)^{\mathrm{A}}$ & $1.11(0.77)^{\mathrm{A}}$ & $0.90(0.30)^{\mathrm{A}}$ & $1.07(0.31)^{\mathrm{A}}$ & $0.90(0.44)^{\mathrm{A}}$ \\
\hline \multirow[t]{2}{*}{ PPAR $\delta$} & $-\mathrm{H}_{2} \mathrm{O}_{2}$ & $1.00(0.25)^{\mathrm{a}}$ & $1.20(0.37)^{\mathrm{a}}$ & $1.19(0.02)^{\mathrm{a}}$ & $0.83(0.09)^{\mathrm{a}}$ & $1.26(0.68)^{\mathrm{a}}$ & $1.40(0.24)^{\mathrm{a}}$ \\
\hline & $+\mathrm{H}_{2} \mathrm{O}_{2}$ & $1.43(0.69)^{\mathrm{A}}$ & $1.87(0.18)^{\mathrm{A}}$ & $1.87(0.55)^{\mathrm{A}}$ & $1.45(0.65)^{\mathrm{A}}$ & $1.33(0.25)^{\mathrm{A}}$ & $1.54(0.15)^{\mathrm{A}}$ \\
\hline \multirow[t]{2}{*}{ PPAR $\gamma$} & $-\mathrm{H}_{2} \mathrm{O}_{2}$ & $1.00(0.16)^{\mathrm{a}}$ & $0.97(0.18)^{\mathrm{a}}$ & $0.89(0.40)^{\mathrm{a}}$ & $1.26(0.35)^{\mathrm{a}}$ & $0.86(0.31)^{\mathrm{a}}$ & $1.12(0.08)^{\mathrm{a}}$ \\
\hline & $+\mathrm{H}_{2} \mathrm{O}_{2}$ & $1.76(0.63)^{\mathrm{A}}$ & $1.67(0.51)^{\mathrm{AB}}$ & $1.22(0.23)^{\mathrm{AB}}$ & $1.46(0.19)^{\mathrm{AB}}$ & $1.61(0.57)^{\mathrm{AB}}$ & $0.84(0.21)^{\mathrm{B}}$ \\
\hline \multirow[t]{2}{*}{ ALOX-5 } & $-\mathrm{H}_{2} \mathrm{O}_{2}$ & $1.00(0.25)^{\mathrm{a}}$ & $0.49(0.26)^{\mathrm{a}}$ & $0.76(0.28)^{\mathrm{a}}$ & $0.71(0.43)^{\mathrm{a}}$ & $0.81(0.39)^{\mathrm{a}}$ & $0.63(0.22)^{\mathrm{a}}$ \\
\hline & $+\mathrm{H}_{2} \mathrm{O}_{2}$ & $1.69(0.60)^{\mathrm{A}}$ & $0.98(0.44)^{\mathrm{AB}}$ & $0.80(0.33)^{\mathrm{AB}}$ & $0.84(0.44)^{\mathrm{AB}}$ & ${ }_{B} .39(0.62)^{\mathrm{A}}$ & $0.51(0.06)^{\mathrm{B}}$ \\
\hline \multirow[t]{2}{*}{ ALOX-12 } & $-\mathrm{H}_{2} \mathrm{O}_{2}$ & $1.00(0.31)^{\mathrm{a}}$ & $0.83(0.43)^{\mathrm{a}}$ & $1.38(0.28)^{\mathrm{a}}$ & $0.55(0.04)^{\mathrm{a}}$ & $0.95(0.24)^{\mathrm{a}}$ & $1.33(0.39)^{\mathrm{a}}$ \\
\hline & $+\mathrm{H}_{2} \mathrm{O}_{2}$ & $1.24(0.94)^{\mathrm{A}}$ & $0.81(0.15)^{\mathrm{A}}$ & $1.13(0.04)^{\mathrm{A}}$ & $1.07(0.75)^{\mathrm{A}}$ & $1.07(0.48)^{\mathrm{A}}$ & $1.24(0.26)^{\mathrm{A}}$ \\
\hline \multicolumn{8}{|c|}{ Antioxidant response } \\
\hline \multirow[t]{2}{*}{ NFE2L2 } & $-\mathrm{H}_{2} \mathrm{O}_{2}$ & $1.00(0.15)^{\mathrm{a}}$ & $1.00(0.17)^{\mathrm{a}}$ & $0.97(0.16)^{\mathrm{a}}$ & $0.93(0.29)^{\mathrm{a}}$ & $0.69(0.03)^{\mathrm{a}}$ & $0.76(0.08)^{\mathrm{a}}$ \\
\hline & $+\mathrm{H}_{2} \mathrm{O}_{2}$ & $1.35(0.37)^{\mathrm{A}}$ & $1.11(0.23)^{\mathrm{AB}}$ & $0.99(0.04)^{\mathrm{AB}}$ & $0.98(0.17)^{\mathrm{AB}}$ & $0.81(0.11)^{\mathrm{B}}$ & $0.77(0.14)^{\mathrm{B}}$ \\
\hline \multirow[t]{2}{*}{ Keap-1 } & $-\mathrm{H}_{2} \mathrm{O}_{2}$ & $1.00(0.18)^{\mathrm{a}}$ & $0.94(0.30)^{\mathrm{a}}$ & $0.92(0.23)^{\mathrm{a}}$ & $0.99(0.09)^{\mathrm{a}}$ & $0.93(0.54)^{\mathrm{a}}$ & $0.81(0.11)^{\mathrm{a}}$ \\
\hline & $+\mathrm{H}_{2} \mathrm{O}_{2}$ & $0.87(0.40)^{\mathrm{A}}$ & $1.04(0.30)^{\mathrm{A}}$ & $0.91(0.26)^{\mathrm{A}}$ & $0.96(0.42)^{\mathrm{A}}$ & $0.84(0.25)^{\mathrm{A}}$ & $0.78(0.02)^{\mathrm{A}}$ \\
\hline \multirow[t]{2}{*}{ GPx-1 } & $-\mathrm{H}_{2} \mathrm{O}_{2}$ & $1.00(0.16)^{\mathrm{a}}$ & $0.99(0.09)^{\mathrm{a}}$ & $0.76(0.17)^{\mathrm{a}}$ & $1.03(0.15)^{\mathrm{a}}$ & $0.70(0.37)^{\mathrm{a}}$ & $0.70(0.10)^{\mathrm{a}}$ \\
\hline & $+\mathrm{H}_{2} \mathrm{O}_{2}$ & $1.40(0.47)^{\mathrm{A}}$ & $1.35(0.20)^{\mathrm{A}}$ & $1.09(0.03)^{\mathrm{AB}}$ & $1.17(0.65)^{\mathrm{AB}}$ & $0.68(0.16)^{\mathrm{B}}$ & $0.59(0.04)^{\mathrm{B}}$ \\
\hline \multirow[t]{2}{*}{ GPx-4 } & $-\mathrm{H}_{2} \mathrm{O}_{2}$ & $1.00(0.18)^{\mathrm{a}}$ & $0.50(0.05)^{\mathrm{a}}$ & $0.92(0.11)^{\mathrm{a}}$ & $0.73(0.29)^{\mathrm{a}}$ & $0.90(0.23)^{\mathrm{a}}$ & $0.72(0.07)^{\mathrm{a}}$ \\
\hline & $+\mathrm{H}_{2} \mathrm{O}_{2}$ & $1.01(0.30)^{\mathrm{A}}$ & $1.03(0.10)^{\mathrm{A}}$ & $0.85(0.30)^{\mathrm{A}}$ & $0.97(0.51)^{\mathrm{A}}$ & $0.94(0.23)^{\mathrm{A}}$ & $0.67(0.21)^{\mathrm{A}}$ \\
\hline \multirow[t]{2}{*}{ SOD-1 } & $-\mathrm{H}_{2} \mathrm{O}_{2}$ & $1.00(0.21)^{\mathrm{a}}$ & $0.82(0.34)^{\mathrm{a}}$ & $0.81(0.23)^{\mathrm{a}}$ & $0.98(0.08)^{\mathrm{a}}$ & $1.17(0.41)^{\mathrm{a}}$ & $0.55(0.19)^{\mathrm{a}}$ \\
\hline & $+\mathrm{H}_{2} \mathrm{O}_{2}$ & $1.17(0.37)^{\mathrm{A}}$ & $1.22(0.20)^{\mathrm{A}}$ & $0.83(0.12)^{\mathrm{A}}$ & $1.21(0.39)^{\mathrm{A}}$ & $1.32(0.37)^{\mathrm{A}}$ & $0.69(0.16)^{\mathrm{A}}$ \\
\hline \multicolumn{8}{|c|}{ Immune response } \\
\hline \multirow[t]{2}{*}{$\mathrm{NF}-\kappa \mathrm{B}$} & $-\mathrm{H}_{2} \mathrm{O}_{2}$ & $1.00(0.15)^{\mathrm{a}}$ & $1.43(0.17)^{\mathrm{a}}$ & $1.09(0.19)^{\mathrm{a}}$ & $1.22(0.45)^{\mathrm{a}}$ & $1.15(0.32)^{\mathrm{a}}$ & $1.32(0.46)^{\mathrm{a}}$ \\
\hline & $+\mathrm{H}_{2} \mathrm{O}_{2}$ & $1.35(0.24)^{\mathrm{A}}$ & $1.39(0.38)^{\mathrm{A}}$ & $1.67(0.53)^{\mathrm{A}}$ & $1.26(0.22)^{\mathrm{A}}$ & $1.23(0.42)^{\mathrm{A}}$ & $1.29(0.53)^{\mathrm{A}}$ \\
\hline \multirow[t]{2}{*}{ IL-6 } & $-\mathrm{H}_{2} \mathrm{O}_{2}$ & $1.00(0.20)^{\mathrm{a}}$ & $1.20(0.43)^{\mathrm{a}}$ & $1.44(0.48)^{\mathrm{a}}$ & $1.05(0.49)^{\mathrm{a}}$ & $1.06(0.26)^{\mathrm{a}}$ & $0.96(0.35)^{\mathrm{a}}$ \\
\hline & $+\mathrm{H}_{2} \mathrm{O}_{2}$ & $1.37(0.21)^{\mathrm{A}}$ & $1.77(0.54)^{\mathrm{A}}$ & $1.42(0.31)^{\mathrm{A}}$ & $1.49(0.65)^{\mathrm{A}}$ & $1.54(0.67)^{\mathrm{A}}$ & $1.04(0.67)^{\mathrm{A}}$ \\
\hline
\end{tabular}

Values expressed in mean (S.D.), $\mathrm{n}=3$. Treatment concentrations were $10 \mu \mathrm{M}$ lutein, $10 \mu \mathrm{M}$ zeaxanthin and $25 \mu \mathrm{M}$ DHA. Different lower-case alphabets indicate statistical differences between treatment groups without hydrogen peroxide $\left(\mathrm{H}_{2} \mathrm{O}_{2}\right)$ challenge; different uppercase alphabets indicate statistical differences between treatment groups with $\mathrm{H}_{2} \mathrm{O}_{2}$ challenge

is predominantly present in the macula and modulates the survival of photoreceptor cells to maintain normal vision [35]. The presence of both carotenoids and DHA in the macula coherently indicates its vital functional properties in oxidative stressed RPE cells.

Elevated ROS are implicated in the pathogenesis of numerous neurodegenerative diseases, including AMD. To withstand the high load of photons and ROS, retinal cells are equipped with endogenous antioxidants to prevent photo-oxidative damage and maintain homeostasis. We demonstrated that a drastic elevation of ROS such as $\mathrm{H}_{2} \mathrm{O}_{2}$ in RPE will modify cell viability and activate CAT but not GSH or SOD. It appears antioxidant modulation to be post-transcriptional as shown by NFE2L2 and ALOX-5. The endogenous antioxidant enzymes were insufficient to reduce intracellular ROS accumulation, resulting in DHA depletion and subsequent oxidation. In addition, epidemiological studies consistently showed low circulating DHA to be highly correlated with risk of developing AMD [4, 37]. Moreover, in both animal and cell models, the deficiency of omega- 3 PUFAs in photoreceptors was related to the development of AMD $[15,38]$. Taken together, our results indicate the treatments were insufficient to regulate the antioxidant enzymes particularly $\mathrm{H}_{2} \mathrm{O}_{2}$ specific CAT, in preventing PUFA oxidation of the $\mathrm{H}_{2} \mathrm{O}_{2}$-stressed RPE cells, and in fact, the DHA depletion via oxidative stress suggest being a predominant contributing factor in pathophysiology of AMD [39].

Little is known about the biological links between oxidized PUFA products (also known as lipid mediators) and the development of AMD. Oxidative stressed RPE cells in this study accumulated a variety of products. These findings provide new insights in the molecular events of lipids in RPE cells following oxidative stress. Past reports indicated the ability of 4-HNE to modify and inactivate retinal proteins by forming adducts that contributes to AMD pathophysiology $[40,41]$. Of note, urinary $15-\mathrm{F}_{2 \mathrm{t}}$-IsoP was previously 
Fig. 2 Levels of antioxidant enzymes of RPE cells $(n=3)$ with or without $600 \mu \mathrm{M} \mathrm{H}_{2} \mathrm{O}_{2}$ challenge. Treatment concentrations were $10 \mu \mathrm{M}$ lutein, $10 \mu \mathrm{M}$ zeaxanthin and $25 \mu \mathrm{M}$ DHA. Values are expressed are mean (S.D.). Different lower-case alphabets indicate statistical differences between treatment groups without $\mathrm{H}_{2} \mathrm{O}_{2}$ challenge; different uppercase capitals indicate statistical differences between treatment groups with $\mathrm{H}_{2} \mathrm{O}_{2}$ challenge; $* * * \mathrm{p}<0.001$ statistical significance with vs without $600 \mu \mathrm{M} \mathrm{H}_{2} \mathrm{O}_{2}$. Zea: zeaxanthin; $\mathrm{L}+\mathrm{Z}$ : lutein plus zeaxanthin; $\mathrm{L}+\mathrm{Z}+\mathrm{D}$ : lutein plus zeaxanthin plus docosahexaenoic acid

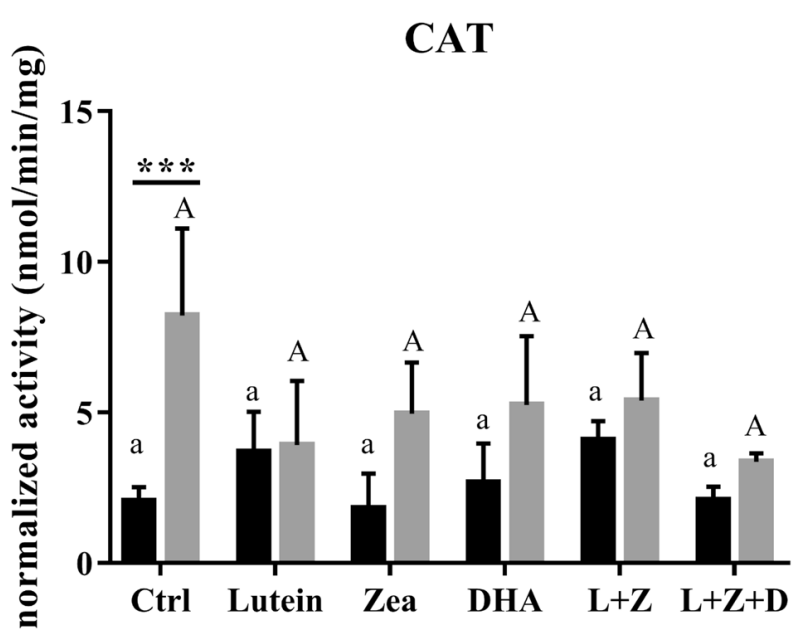

SOD

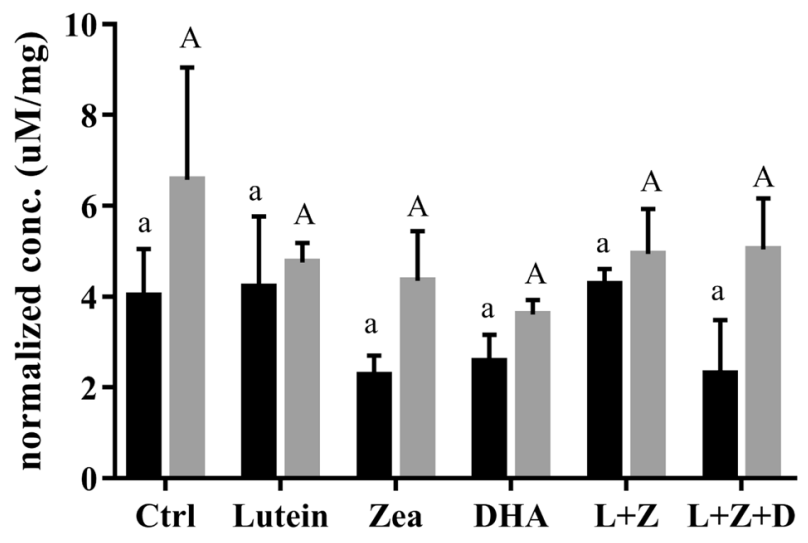

without $\mathrm{H}_{2} \mathrm{O}_{2}$

$600 \mu \mathrm{M} \mathrm{H}_{2} \mathrm{O}_{2}$

\section{GSH}

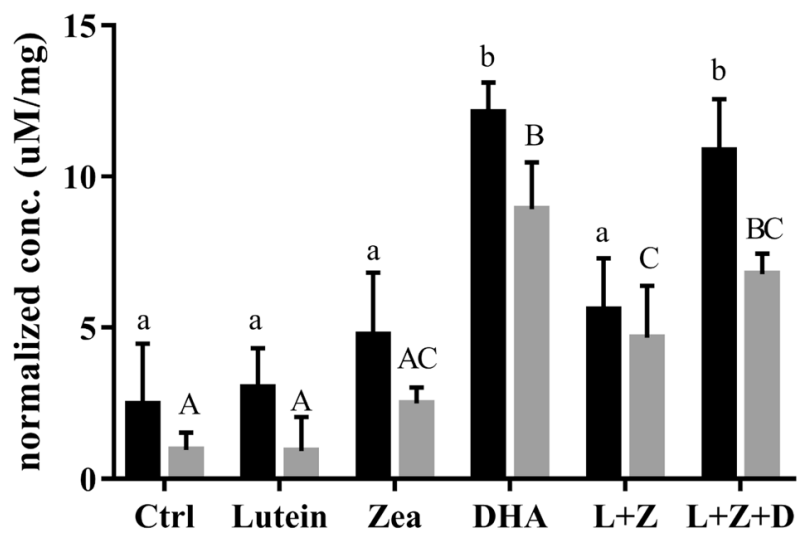

found to be associated with neovascular AMD development [42], whereas elevated 4-HNE was reported in patients with neurodegenerative diseases [43]. Furthermore, recent report showed increased systemic $4-\mathrm{F}_{4 \mathrm{t}}-\mathrm{NeuroP}$ and $10-\mathrm{F}_{4 \mathrm{t}}-\mathrm{NeuroP}$ in Rett Syndrome patients and other neurological diseases, which suggests them to be potential markers for neurodegeneration including AMD [39]. It is noted 4- $\mathrm{F}_{4 \mathrm{t}}-\mathrm{NeuroP}$ levels showed stronger suppression by lutein + zeaxanthin 
than DHA alone in the $\mathrm{H}_{2} \mathrm{O}_{2}$-stressed RPE cells in our observation. This suppression remained when the three were combined. This contradicts to our recent findings [39] where decrease in omega-3 PUFA oxidation, in particular NeuroPs and HDHA enhanced the risk of AMD subjects however, such observation was attributed by low circulating DHA. Although the use of RPE cell line cannot fully represent the human body, our findings suggests sufficient DHA and carotenoids are essential for homeostatic control in oxidative damage of the RPE cells, perhaps through intracellular antioxidant gene expressions.

Taking into account that ROS induces PUFA oxidation and contributes to AMD progression, it of interest to see if supplementation with carotenoids and DHA lessen oxidative damages. Lutein and zeaxanthin are lipid antioxidants and anticipated to protect cellular PUFA from ROS attack. Single treatment of lutein, zeaxanthin, DHA, or lutein + zeaxanthin did not reduce PUFA oxidation or induce changes in cellular gene expressions in this study. Lipoxygenasemediated DHA oxidation products including NPD1 were increased after treatment with DHA. NPD1 is reported to support homeostatic regulation of retinal epithelial and photoreceptor cell integrity, particularly under oxidative stress [44].

On contrary, combination of lutein + zeaxanthin with DHA possibly protected RPE cells from ROS attack in multiple ways. For instance, it conserved a considerable portion of DHA even under oxidative stress, and simultaneously elevated RvD1, NPD1 and 17-HDHA. These are known to be neuroprotective but insofar its exact role in retinal cells is unknown, except for NPD1. HDHAs are anti-inflammatory and with the pro-resolving RvD, they can possibly prevent degeneration of RPE cells. Nevertheless, when considering how cell culture media also imposes a state of oxidative stress on cells [45], it is uncertain whether the production of these DHA mediators is a cellular event or just a catalysed oxidation caused by ROS in the media.

Expressions of antioxidant related transcriptional factors such as NFE2L2 and PPAR $\gamma$ were suppressed in $\mathrm{H}_{2} \mathrm{O}_{2}$-stressed RPE cells when treated with lutein + zeaxanthin or with DHA respectively. In addition, down-regulation of ALOX- 5 by lutein + zeaxanthin with DHA and GPX-1 by lutein + zeaxanthin was also observed and coincides with HETEs reduction and GSH elevation respectively. Such observation consistently indicates the combined treatment of lutein + zeaxanthin is protective to retinal cells where a recent report suggested the depletion of GSH induced ferroptosis, autophagy, and more importantly, premature cell senescence in RPE cells [46].

It was anticipated carotenoids and DHA together in the retinal cells would protect each other from oxidation, increase its bioavailability and prevent the formation of toxic compounds like HNE. Our study did not show such kind of protection and in fact, lutein and zeaxanthin were unable to rescue the low cell viability induced by $\mathrm{H}_{2} \mathrm{O}_{2}$. DHA treatment was reported to reduce apoptosis and induce a transient increase in ROS in RPE cells, where the subtoxic stress can activate the antioxidant stress response transcription factor NFE2L2/NRF2 (nuclear respiratory factor) that controls the transcriptional encoding of the genes related to endogenous enzymatic and nonenzymatic antioxidants [47]. However, in this study it appears that DHA was unable to induce endogenous antioxidants in RPE cells, thus prevent ROS-driven cell apoptosis.

Although we did not measure both carotenoids in the RPE cells, the uptake may have been limited as they are transported in vivo by lipoproteins (LDL, HDL) [48]. Further, retinal lutein and zeaxanthin may have preferentially formed complexes with ocular proteins. A study reported that the $\mathrm{Pi}$ isoforms of glutathione transferase protein (GSTPi) in human macula have greater interaction with zeaxanthin, but not lutein [49]. However, in this study, it was also possible $\mathrm{H}_{2} \mathrm{O}_{2}$ modified the cellular protein and prevented the formation of the complex. Moreover, membrane-bound lutein is believed to scavenge oxidants by quenching reactive oxygen intermediates through a large number of unbound double bonds in the lutein molecule [50]. The orientation of lutein in the cellular membrane may affect its antioxidant efficiency. Normally, dipolar carotenoids including lutein is located and distributed within the cellular membrane in a vertical manner. Nonetheless, its distribution in retinal cells varies when bound to proteins [51] and transferred into the lipid membrane of the retinal cells. The proximity of transmembrane lutein with polyunsaturated phospholipids allow optimal protection against ROS.

To conclude, $\mathrm{H}_{2} \mathrm{O}_{2}$ depleted DHA and enhanced lipid oxidation in RPE cells. Seemingly, lutein and zeaxanthin when combined provided better cellular protection from oxidative stress related to non-enzymatic oxidation while DHA displayed its protection by reducing the production of pro-inflammatory mediators of omega-6 PUFA through PPAR $\gamma$ and ALOX-5 inhibition, and the augmentation of anti-inflammatory mediators of omega-3 PUFA. The combination of lutein, zeaxanthin and DHA did not further benefit in cell protection from oxidative damage and appeared to be mutually exclusive.

Acknowledgements We thank Drs Laurence Balas, Camille Oger and Aurélien de La Torre (IBMM, Montpellier, France) for the synthesis of analytical standards.

Funding This work was supported by Health and Medical Research Fund (No. 13142301), Food and Health Bureau, Hong Kong.

\section{Compliance with Ethical Standards}

Conflict of interest The authors declare no conflict of interest. 


\section{References}

1. Kijlstra A, Berendschot TT (2015) Age-related macular degeneration: a complementopathy? Ophthalmic Res 54:64-73

2. Muller FL, Lustgarten MS, Jang Y, Richardson A, Van Remmen $\mathrm{H}$ (2007) Trends in oxidative aging theories. Free Radic Biol Med 43:477-503

3. Joachim N, Kifley A, Colijn JM, Lee KE, Buitendijk GHS, Klein BEK, Myers C, Meuer SM, Tan AG, Flood V, Schoufour JD, Franco OH, Holliday EG, Attia J, Liew G, Iyengar SK, de Jong P, Hofman A, Vingerling JR, Mitchell P, Klein R, Klaver CCW, Wang JJ (2018) Joint contribution of genetic susceptibility and modifiable factors to the progression of age-related macular degeneration over 10 years: the three continent amd consortium report. Ophthalmol Retina 2:684-693

4. Ng AL, Leung HH, Kawasaki R, Ho WL, Chow LL, Chow SS, Lee JC, Wong IY (2019) Dietary habits, fatty acids and carotenoid levels are associated with neovascular age-related macular degeneration in Chinese. Nutrients. https://doi.org/10.3390/ nu11081720

5. Age-Related Eye Disease Study Research G (2001) A randomized, placebo-controlled, clinical trial of high-dose supplementation with vitamins $\mathrm{C}$ and $\mathrm{E}$, beta carotene, and zinc for age-related macular degeneration and vision loss: AREDS report no. 8. Arch Ophthalmol 119:1417-1436

6. Age-Related Eye Disease Study 2 Research G (2013) Lutein + zeaxanthin and omega-3 fatty acids for age-related macular degeneration: the Age-Related Eye Disease Study 2 (AREDS2) randomized clinical trial. JAMA 309:2005-2015

7. Eisenhauer B, Natoli S, Liew G, Flood VM (2017) Lutein and zeaxanthin-food sources, bioavailability and dietary variety in age-related macular degeneration protection. Nutrients. https:// doi.org/10.3390/nu9020120

8. Joachim N, Mitchell P, Burlutsky G, Kifley A, Wang JJ (2015) The incidence and progression of age-related macular degeneration over 15 years: the Blue Mountains eye study. Ophthalmology 122:2482-2489

9. Souied EH, Aslam T, Garcia-Layana A, Holz FG, Leys A, Silva R, Delcourt C (2015) Omega-3 fatty acids and age-related macular degeneration. Ophthalmic Res 55:62-69

10. Georgiou TN, Nicolaou D, Sears B (2014) Pilot study for treating dry age-related macular degeneration (AMD) with highdose omega-3 fatty acids. Pharm Nutr 2:8-11

11. Al-Zamil WM, Yassin SA (2017) Recent developments in age-related macular degeneration: a review. Clin Interv Aging 12:1313-1330

12. Bellezza I (2018) Oxidative stress in age-related macular degeneration: Nrf2 as therapeutic target. Front Pharmacol 9:1280

13. Dunn KC, Aotaki-Keen AE, Putkey FR, Hjelmeland LM (1996) ARPE-19, a human retinal pigment epithelial cell line with differentiated properties. Exp Eye Res 62:155-169

14. Liu H, Liu W, Zhou X, Long C, Kuang X, Hu J, Tang Y, Liu L, He J, Huang Z, Fan Y, Jin G, Zhang Q, Shen H (2017) Protective effect of lutein on ARPE-19 cells upon $\mathrm{H}_{2} \mathrm{O}_{2}$-induced G2/M arrest. Mol Med Rep 16:2069-2074

15. Bazan NG (2006) Survival signaling in retinal pigment epithelial cells in response to oxidative stress: significance in retinal degenerations. Adv Exp Med Biol 572:531-540

16. Galano JM, Lee JC, Gladine C, Comte B, Le Guennec JY, Oger C, Durand T (2015) Non-enzymatic cyclic oxygenated metabolites of adrenic, docosahexaenoic, eicosapentaenoic and alphalinolenic acids; bioactivities and potential use as biomarkers. Biochim Biophys Acta 1851:446-455

17. Ikei KN, Yeung J, Apopa PL, Ceja J, Vesci J, Holman TR, Holinstat M (2012) Investigations of human platelet-type 12-lipoxygenase: role of lipoxygenase products in platelet activation. J Lipid Res 53:2546-2559

18. Sapieha P, Stahl A, Chen J, Seaward MR, Willett KL, Krah NM, Dennison RJ, Connor KM, Aderman CM, Liclican E, Carughi A, Perelman D, Kanaoka Y, Sangiovanni JP, Gronert K, Smith LEH (2011) 5-Lipoxygenase metabolite 4-HDHA is a mediator of the antiangiogenic effect of-3 polyunsaturated fatty acids. Sci Transl Med. https://doi.org/10.1126/scitranslmed.3001571

19. Roberts LJ, Morrow JD (2000) Measurement of F(2)-isoprostanes as an index of oxidative stress in vivo. Free Radic Biol Med 28:505-513

20. Bauer J, Ripperger A, Frantz S, Ergun S, Schwedhelm E, Benndorf RA (2014) Pathophysiology of isoprostanes in the cardiovascular system: implications of isoprostane-mediated thromboxane A2 receptor activation. Br J Pharmacol $171: 3115-3131$

21. Roy J, Fauconnier J, Oger C, Farah C, Angebault-Prouteau C, Thireau J, Bideaux P, Scheuermann V, Bultel-Ponce V, Demion M, Galano JM, Durand T, Lee JC, Le Guennec JY (2017) Nonenzymatic oxidized metabolite of DHA, 4(RS)-4-F4t-neuroprostane protects the heart against reperfusion injury. Free Radic Biol Med 102:229-239

22. Galano J-M, Lee YY, Oger C, Vigor C, Vercauteren J, Durand T, Giera M, Lee JC-Y (2017) Isoprostanes, neuroprostanes and phytoprostanes: an overview of 25 years of research in chemistry and biology. Prog Lipid Res 68:83-108

23. Makarev E, Cantor C, Zhavoronkov A, Buzdin A, Aliper A, Csoka AB (2014) Pathway activation profiling reveals new insights into age-related macular degeneration and provides avenues for therapeutic interventions. Aging (Albany NY) 6:1064-1075

24. Herzlich AA, Ding X, Shen D, Ross RJ, Tuo J, Chan CC (2009) Peroxisome proliferator-activated receptor expression in murine models and humans with age-related macular degeneration. Open Biol J 2:141-148

25. Sliwinski T, Kolodziejska U, Szaflik JP, Blasiak J, Szaflik J (2013) Association between the $25129 \mathrm{~A} \% 3 \mathrm{e}$ C polymorphism of the nuclear respiratory factor 2 gene and age-related macular degeneration. Klin Oczna 115:96-102

26. Frede K, Ebert F, Kipp AP, Schwerdtle T, Baldermann S (2017) Lutein activates the transcription factor Nrf2 in human retinal pigment epithelial cells. J Agric Food Chem 65:5944-5952

27. Li Y, Zou X, Cao K, Xu J, Yue T, Dai F, Zhou B, Lu W, Feng Z, Liu J (2013) Curcumin analog 1,5-bis (2-trifluoromethylphenyl)1,4-pentadien-3-one exhibits enhanced ability on Nrf2 activation and protection against acrolein-induced ARPE-19 cell toxicity. Toxicol Appl Pharmacol 272:726-735

28. Lee YY, Lee JC (2018) LC-MS/MS analysis of lipid oxidation products in blood and tissue samples. Methods Mol Biol 1730:83-92

29. Giustarini D, Dalle-Donne I, Milzani A, Fanti P, Rossi R (2013) Analysis of GSH and GSSG after derivatization with $N$-ethylmaleimide. Nat Protoc 8:1660-1669

30. Weydert CJ, Cullen JJ (2010) Measurement of superoxide dismutase, catalase and glutathione peroxidase in cultured cells and tissue. Nat Protoc 5:51-66

31. Johansson LH, Borg LA (1988) A spectrophotometric method for determination of catalase activity in small tissue samples. Anal Biochem 174:331-336

32. Wheeler CR, Salzman JA, Elsayed NM, Omaye ST, Korte DW $\mathrm{Jr}$ (1990) Automated assays for superoxide dismutase, catalase, glutathione peroxidase, and glutathione reductase activity. Anal Biochem 184:193-199

33. Smith PK, Krohn RI, Hermanson GT, Mallia AK, Gartner FH, Provenzano MD, Fujimoto EK, Goeke NM, Olson BJ, Klenk DC (1985) Measurement of protein using bicinchoninic acid. Anal Biochem 150:76-85 
34. Yeum KJ, Taylor A, Tang G, Russell RM (1995) Measurement of carotenoids, retinoids, and tocopherols in human lenses. Invest Ophthalmol Vis Sci 36:2756-2761

35. Shindou H, Koso H, Sasaki J, Nakanishi H, Sagara H, Nakagawa KM, Takahashi Y, Hishikawa D, Iizuka-Hishikawa Y, Tokumasu F, Noguchi H, Watanabe S, Sasaki T, Shimizu T (2017) Docosahexaenoic acid preserves visual function by maintaining correct disc morphology in retinal photoreceptor cells. J Biol Chem 292:12054-12064

36. Stahl W (2005) Macular carotenoids: lutein and zeaxanthin. Dev Ophthalmol 38:70-88

37. Merle BM, Benlian P, Puche N, Bassols A, Delcourt C, Souied EH, Nutritional AMDTSG (2014) Circulating omega-3 fatty acids and neovascular age-related macular degeneration. Invest Ophthalmol Vis Sci 55:2010-2019

38. Anderson RE, Maude MB, McClellan M, Matthes MT, Yasumura D, LaVail MM (2002) Low docosahexaenoic acid levels in rod outer segments of rats with $\mathrm{P} 23 \mathrm{H}$ and $\mathrm{S} 334$ ter rhodopsin mutations. Mol Vis 8:351-358

39. Signorini C, De Felice C, Galano JM, Oger C, Leoncini S, Cortelazzo A, Ciccoli L, Durand T, Hayek J, Lee JC (2018) Isoprostanoids in clinical and experimental neurological disease models. Antioxidants (Basel). https://doi.org/10.3390/antiox7070088

40. Ethen CM, Reilly C, Feng X, Olsen TW, Ferrington DA (2007) Age-related macular degeneration and retinal protein modification by 4-hydroxy-2-nonenal. Invest Ophthalmol Vis Sci 48:3469-3479

41. Shoeb M, Ansari NH, Srivastava SK, Ramana KV (2014) 4-Hydroxynonenal in the pathogenesis and progression of human diseases. Curr Med Chem 21:230-237

42. Sabanayagam C, Lye WK, Januszewski A, Banu B, Mohammed AR, Cheung GCM, Kumari N, Wong TY, Cheng CY, Lamoureux E (2017) Urinary isoprostane levels and age-related macular degeneration. Invest Ophthalmol Vis Sci 58:2538-2543

43. Csala M, Kardon T, Legeza B, Lizak B, Mandl J, Margittai E, Puskas F, Szaraz P, Szelenyi P, Banhegyi G (2015) On the role of 4-hydroxynonenal in health and disease. Biochim Biophys Acta 1852:826-838
44. Bazan NG (2009) Neuroprotectin D1-mediated anti-inflammatory and survival signaling in stroke, retinal degenerations, and Alzheimer's disease. J Lipid Res 50(Suppl):S400-405

45. Halliwell B, Whiteman M (2004) Measuring reactive species and oxidative damage in vivo and in cell culture: how should you do it and what do the results mean? Br J Pharmacol 142:231-255

46. Sun Y, Zheng Y, Wang C, Liu Y (2018) Glutathione depletion induces ferroptosis, autophagy, and premature cell senescence in retinal pigment epithelial cells. Cell Death Dis 9:753

47. Johansson I, Monsen VT, Pettersen K, Mildenberger J, Misund K, Kaarniranta K, Schonberg S, Bjorkoy G (2015) The marine n-3 PUFA DHA evokes cytoprotection against oxidative stress and protein misfolding by inducing autophagy and NFE2L2 in human retinal pigment epithelial cells. Autophagy 11:1636-1651

48. Goulinet S, Chapman MJ (1997) Plasma LDL and HDL subspecies are heterogenous in particle content of tocopherols and oxygenated and hydrocarbon carotenoids. Relevance to oxidative resistance and atherogenesis. Arterioscler Thromb Vasc Biol 17(4), 786-796.

49. Bhosale P, Larson AJ, Frederick JM, Southwick K, Thulin CD, Bernstein PS (2004) Identification and characterization of a Pi isoform of glutathione S-transferase (GSTP1) as a zeaxanthinbinding protein in the macula of the human eye. J Biol Chem 279:49447-49454

50. Woodall AA, Lee SW, Wessie RJ, Jackson MJ, Britton G (1997) Oxidation of carotenoids by free radicals: relationship between structure and reactivity. Biochim Biophys Acta 1336:33-42

51. Subczynski WK, Wisniewska A, Widomska J (2010) Location of macular xanthophylls in the most vulnerable regions of photoreceptor outer-segment membranes. Arch Biochem Biophys 504:61-66 